\title{
Dopamine-Modulated Recurrent Corticoefferent Feedback in Primary Sensory Cortex Promotes Detection of Behaviorally Relevant Stimuli
}

\author{
Max F. K. Happel, ${ }^{1,2 *}$ Matthias Deliano, ${ }^{1 *}$ Juliane Handschuh, ${ }^{1}$ and Frank W. Ohl ${ }^{1,2,3}$ \\ ${ }^{1}$ Leibniz Institute for Neurobiology, D-39118 Magdeburg, Germany, ${ }^{2}$ Institute of Biology, Otto-von-Guericke-University, D-39120 Magdeburg, Germany, \\ and ${ }^{3}$ Center for Behavioral Brain Sciences, D-39118 Magdeburg, Germany
}

\begin{abstract}
Dopaminergic neurotransmission in primary auditory cortex (AI) has been shown to be involved in learning and memory functions. Moreover, dopaminergic projections and $\mathrm{D}_{1} / \mathrm{D}_{5}$ receptor distributions display a layer-dependent organization, suggesting specific functions in the cortical circuitry. However, the circuit effects of dopaminergic neurotransmission in sensory cortex and their possible roles in perception, learning, and memory are largely unknown.

Here, we investigated layer-specific circuit effects of dopaminergic neuromodulation using current source density (CSD) analysis in AI of Mongolian gerbils. Pharmacological stimulation of $\mathrm{D}_{1} / \mathrm{D}_{5}$ receptors increased auditory-evoked synaptic currents in infragranular layers, prolonging local thalamocortical input via positive feedback between infragranular output and granular input. Subsequently, dopamine promoted sustained cortical activation by prolonged recruitment of long-range corticocortical networks. A detailed circuit analysis combining layer-specific intracortical microstimulation (ICMS), CSD analysis, and pharmacological cortical silencing revealed that cross-laminar feedback enhanced by dopamine relied on a positive, fast-acting recurrent corticoefferent loop, most likely relayed via local thalamic circuits. Behavioral signal detection analysis further showed that activation of corticoefferent output by infragranular ICMS, which mimicked auditory activation under dopaminergic influence, was most effective in eliciting a behaviorally detectable signal.

Our results show that $\mathrm{D}_{1} / \mathrm{D}_{5}$-mediated dopaminergic modulation in sensory cortex regulates positive recurrent corticoefferent feedback, which enhances states of high, persistent activity in sensory cortex evoked by behaviorally relevant stimuli. In boosting horizontal network interactions, this potentially promotes the readout of task-related information from cortical synapses and improves behavioral stimulus detection.
\end{abstract}

Key words: auditory cortex; behavior; corticoefferent recurrence; dopamine; perception

\section{Introduction}

The auditory cortex is a relevant structure for task-related processing of auditory information and for formation of memories about the behavioral relevance of acoustic signals (Ohl et al., 2001; Ohl and Scheich, 2005; Dahmen et al., 2010; Scheich et al., 2011). Using a cortex-dependent auditory learning paradigm (Ohl et al., 1999), it was previously shown that long-term memory formation depends on transient and local intracortical dopamine release (Stark and Scheich, 1997; Stark et al., 2008) mediating protein synthesis-dependent plasticity in auditory cortex (Kraus et al., 2002; Schicknick et al., 2008, 2012). While the neuromodulatory actions of dopamine are increasingly well

\footnotetext{
Received May 12, 2013; revised 0ct. 23, 2013; accepted Nov. 24, 2013

Author contributions: M.F.K.H., M.D., and F.W.O. designed research; M.F.K.H. and J.H. performed research; M.F.K.H. and M.D. analyzed data; M.F.K.H., M.D., and F.W.O. wrote the paper.

This work was supported by Deutsche Forschungsgemeinschaft Grants SFB TRR 31 and SFB 779. We thank K. Ohl for technical assistance.

${ }^{*}$ M.F.K.H. and M.D. contributed equally to this work.

This article is freely available online through the J Neurosci Author Open Choice option.

Correspondence should be addressed to Max F. K. Happel, Matthias Deliano, or Frank W. Ohl, Leibniz

Institute for Neurobiology, D-39118 Magdeburg, Germany, E-mail: max.happel@lin-magdeburg.de,

matthias.deliano@lin-magdeburg.de, or frank.ohl@lin-magdeburg.de.

DOI:10.1523/JNEUROSCI.1990-13.2014

Copyright $\odot 2014$ the authors $\quad 0270-6474 / 14 / 341234-14 \$ 15.00 / 0$
}

characterized in prefrontal cortical and midbrain neuronal circuits (Tritsch and Sabatini, 2012), the consequences of dopaminergic modulations in primary sensory areas are less well understood. Dopaminergic fibers and $\mathrm{D}_{1} / \mathrm{D}_{5}$ receptors are most abundant in the infragranular output layers V and VI across species in primary auditory cortex (Campbell et al., 1987; Phillipson et al., 1987; Schicknick et al., 2008) and other cortices (Krimer et al., 1997). Therefore, it could be hypothesized that dopamine intracortically released in infragranular layers unfolds its action by modulating the infragranular corticoefferent output of the cortical circuitry (Phillipson et al., 1987). Dopaminergic neurons are thought to signal the motivational value, salience, and importance of sensory cues (Bromberg-Martin et al., 2010). Dopaminergic neuromodulation of corticoefferent output might therefore contribute to the balanced integration of top-down information and bottom-up sensory input (King, 1997), and might be involved in predictive coding (Bastos et al., 2012; Friston et al., 2012). Yet, whereas specific neuromodulatory circuit functions (Hasselmo, 1995) have been already demonstrated for the cholinergic modulation of sensory thalamocortical input (Metherate et al., 2005; Kawai et al., 2007; Edeline, 2012), layer-dependent circuit effects of dopaminergic neuromodulation in sensory cortex are poorly understood. 


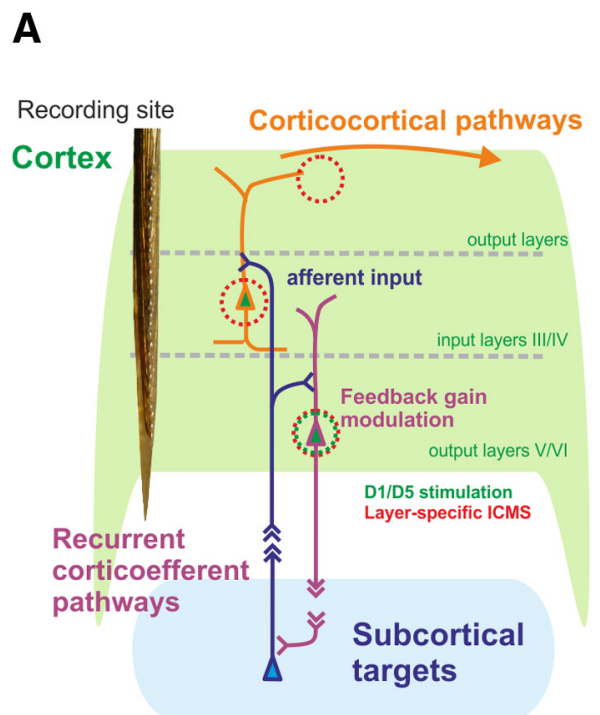

B

D

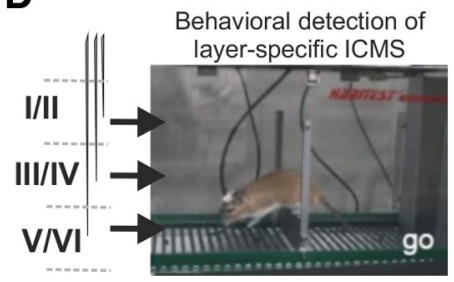

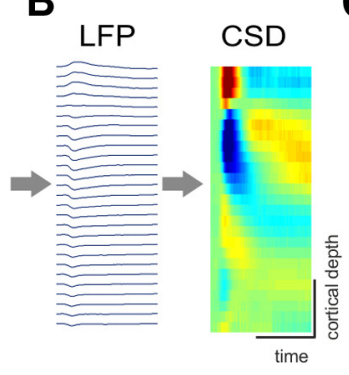

Figure 1. Schematic overview of the experimental design. $\boldsymbol{A}$, Experimental setting for electrophysiological recordings and layer-specific modulation of activity using (1) pharmacological activation of $D_{1} / D_{5}$ receptors predominantly located within infragranular, corticoefferent layers (green circles) or (2) intracortical microstimulation at different cortical depths (red circles). $\boldsymbol{B}$, Laminar LFP recordings were used for CSD analysis to determine spatiotemporal patterns of synaptic current flow (Happel et al., 2010) required for a layer-specific interpretation of electrically and auditory evoked activity in relation to the underlying local cortical microcircuitry at the recording site. Stimulation and recording electrodes were positioned along the rostrocaudal axis of AI to target different tonotopic regions (Budinger et al., 2006). C, Location of the stimulation channels across the cortical layers indicated by Prussian blue staining, as used for electrophysiology and behavior (see Materials and Methods). Indicated are the electrode tracks of the stimulation electrode. Inset at bottom shows a cross section of the vertically aligned lateral stimulation array. Scale bar, $200 \mu \mathrm{m}$. D, Illustration of the behavioral paradigm: Go/NoGo task for investigating behavioral detection of ICMS in a shuttlebox, in order for establish relationships between perception and the recruitment of different corticocortical and recurrent corticoefferent pathways through layer-specific ICMS.

By exploiting a previously established technique to dissociate intracortically relayed components from thalamocortically relayed components of cortical stimulus-induced excitation (Happel et al., 2010), we investigated the effects of dopaminergic neuromodulation in primary auditory cortex (AI) of Mongolian gerbils on a systems level. In a stepwise approach of circuit analysis, using auditory stimulation, layer-specific intracortical microstimulation (ICMS), laminar current-source-density (CSD) analysis (Mitzdorf, 1985; Happel et al., 2010), pharmacological manipulation, and behavioral analysis (Fig. 1), we showed that administration of $D_{1} / D_{5}$ dopamine receptor agonist SKF38393 enhanced early infragranular auditory-evoked synaptic activity, prolonged

auditory activation, and more effectively recruited horizontal corticocortical networks during later phases of processing. Moreover, cross-correlation analysis of layer-dependent sinks and a detailed circuit analysis combining ICMS and cortical inactivation with $\mathrm{GABA}_{\mathrm{A}}$ agonist muscimol revealed that dopamine enhanced fast-acting positive feedback between infragranular output and granular input layers, most likely via thalamically relayed local recurrent corticoefferent pathways. Direct excitation of corticoefferent output yielded the highest behavioral signal detection performance, whereas direct excitation of horizontal corticocortical pathways did not contribute to detection.

Together, these results indicate that a locally organized cortico-thalamocortical positive-feedback circuit in AI serves as a $\mathrm{D}_{1} / \mathrm{D}_{5}$-modulated gain regulation mechanism enhancing horizontal intracortical processing, and further that this mechanism promotes the readout of task-related information from cortical synapses, thereby improving salient stimulus detection.

\section{Materials and Methods}

Experiments were performed in adult male Mongolian gerbils (Meriones unguiculatus; age, 3-16 months; body weight, $80-120 \mathrm{~g}$ ). For acute electrophysiological experiments, 20 ketamine-xylazine-anesthetized animals have been used ( $n=8$ for auditory stimulation, $n=$ 12 for ICMS-based circuit analysis). For behavioral training, 10 animals have been chronically implanted with stimulation electrodes and trained in a shuttlebox paradigm. Experiments were conducted in accordance with ethical animal research standards defined by German law and approved by an ethics committee of the state of Saxony-Anhalt, Germany.

Surgical procedure. Surgery and preparation for the acute experiment have been conducted as described in detail previously (Happel et al., 2010). Animals were anesthetized by intraperitoneal perfusion $(0.06 \mathrm{ml} / \mathrm{h})$ of $45 \%$ ketamine (50 mg/ml, Ratiopharm), 5\% xylazine (2\% Rompun, Bayer Vital), and 50\% isotonic sodium chloride solution (154 mmol/L, Braun). Right auditory cortex was exposed by craniotomy $(\sim 3 \times 4 \mathrm{~mm})$ of the temporal bone, and the dura was cut immediately before insertion of the recording and stimulation electrodes. For chronic implantation in behavioral experiments, a small hole $(\varnothing=0.3 \mathrm{~mm})$ was drilled in the region of right auditory cortex identified by the blood-brain vessel signature, and stimulation electrodes and connectors were fixed to the skull with dental acrylic. In both, acute and chronic experiments, a reference electrode (gold-plated pin) for stimulation and recording was implanted in the contralateral parietal bone with good contact to the dura.

Electrophysiological recordings and stimulation parameters. Depth profiles of local field potentials (LFPs) were recorded using custom-made shaft electrodes (linear array of 24-28 contacts with a spacing of 55-70 $\mu \mathrm{m}$ spanning $\sim 1600 \mu \mathrm{m}$ ) implanted perpendicular to the cortical layers with upper contact at the surface (Happel et al., 2010). Recorded potentials were preamplified $(500 \times)$, bandpass filtered between 3 and $170 \mathrm{~Hz}$ ( $3 \mathrm{~dB}$ cutoff frequency), and digitized at $2 \mathrm{kHz}$ with a multichannel recording system (Multichannel Acquisition Processor, Plexon Inc.). Experiments were performed in an acoustically and electrically shielded recording chamber. Primary auditory cortex field AI was identified by vascular landmarks and physiological parameters (Ohl et al., 1999, 2000, 2001; Happel et al., 2010).

In the first part of the study, we investigated the influence of increased cortical dopaminergic neurotransmission by systemic application of the $\mathrm{D}_{1} / \mathrm{D}_{5}$ agonist SKF38393 (5 mg/kg, i.p.; Schicknick et al., 2008) on auditory-evoked CSD profiles $(n=8)$. Pseudorandomized presentation of pure tone frequencies ( $65 \mathrm{~dB}$ SPL, $200 \mathrm{~ms}, 5 \mathrm{~ms}$ sinusoidal ramp, $0.8-1$ s interstimulus interval, 50 stimulus repetitions) varied between 0.25 and $16.0 \mathrm{kHz}$ to determine the best frequency, as has been demonstrated previously (Happel et al., 2010). After insertion of the multielectrode, we waited at least $30 \mathrm{~min}$ before application of the $\mathrm{D}_{1} / \mathrm{D}_{5}$ agonist and proceeded only when the auditory-evoked CSD patterns were stable by means of sinks and corresponding channels across several recordings. We compared CSD profiles evoked with the best frequency in untreated $\mathrm{AI}$ and 20 min after application of SKF38393. Stability of the recording axis throughout the experiment was additionally controlled by application of the competitive $\mathrm{D}_{1} / \mathrm{D}_{5}$ antagonist $\mathrm{SCH} 23390(0.1 \mathrm{mg} / \mathrm{kg}$, i.p.; Schicknick et al., 2008) $>60 \mathrm{~min}$ after application of the agonist to reverse its effect (Fig. 2B). Best frequencies in our experiments ranged from low to mid frequencies $(1-12 \mathrm{kHz}$ ) without obvious differences between 
A

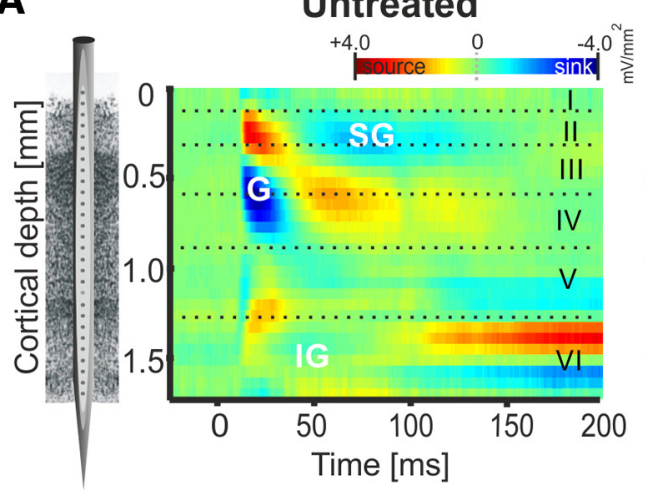

\section{Sink mean amplitude}

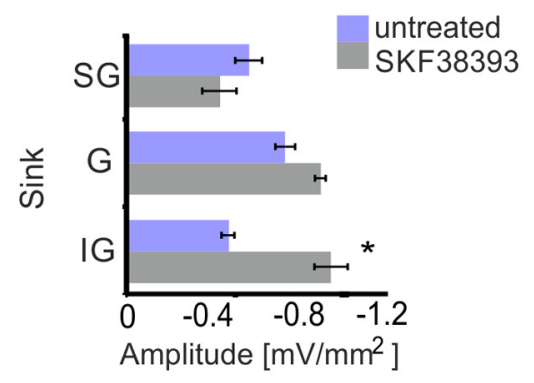

SKF38393

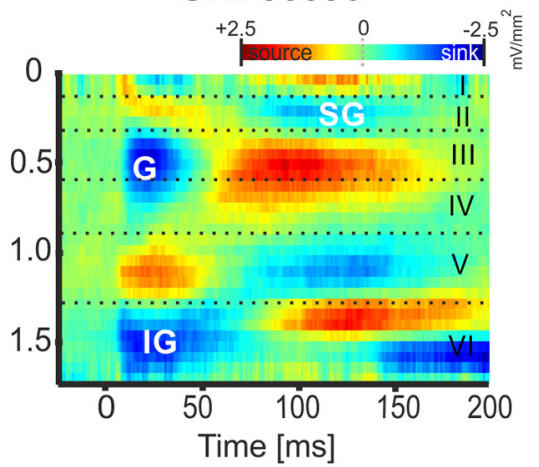

B Laminar sink extent

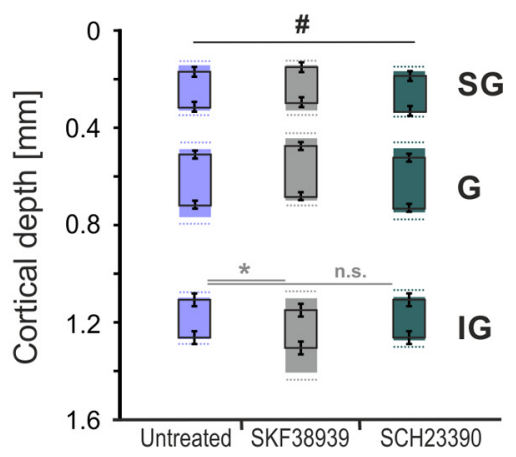

D Early and late processing

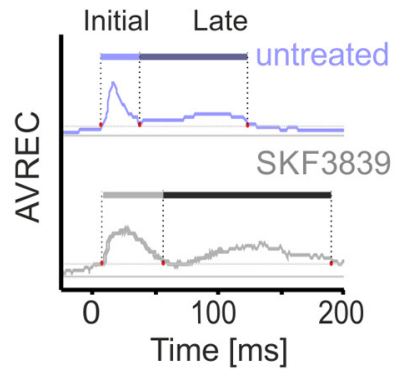

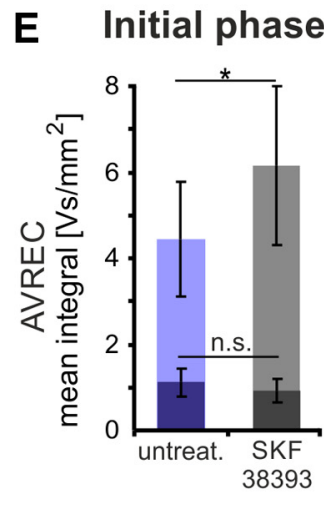

Late phase

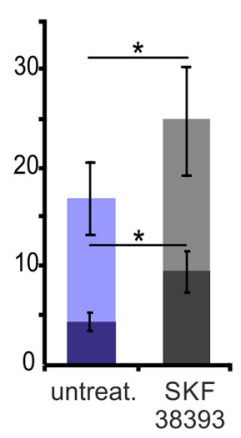

Figure 2. Interaction between thalamocortical input and corticoefferent output layers induced by dopaminergic stimulation. $\boldsymbol{A}$, Pure-tone evoked CSD profile in response to best-frequency stimulation ( $2 \mathrm{kHz}$ in the example shown) revealed a canonical polysynaptic cascade of laminar cortical processing in primary auditory cortex (left). Cortical activation commences in granular input layers and entails extragranular activations ( $G$ sink followed by subsequent extragranular IG and SG sinks). Application of $D_{1} / D_{5}$ agonist SKF38393 increased short-latency, early infragranular sink activation that correlated with stronger synaptic current flow in granular layers (see $\boldsymbol{D}$ ) within a time window of $\sim 25$ ms after tone-evoked onset (right). (ortical layers indicated here and the following CSD plots were derived from histological analysis and represent mean relations in gerbil AI (Happel et al., 2010). B, Laminar extent of individual SG, G, and IG sinks in untreated cortex and after application of $D_{1} / D_{5}$ agonist SKF38393 and antagonist $S C H 23390$, demonstrating recording track stability throughout and across the experiments. Channels with the shortest onset latencies chosen for averaging (see Materials and Methods) were not significantly different across conditions (black boxes, \#; paired-sample Student's $t$ test). The full spatial extent of corresponding sink components including channels with longer onset latencies not used for averaging (colored rectangles; dashed lines, SEM) significantly increased with the application of SKF38939 only for IG sink. This effect was reversed after the application of the antagonist ( ${ }^{*}$ paired-sample Student's $t$ test; see Results). C, Cumulative mean peak amplitudes from onset to peak within different layers before and after SKF38393 application. D, Duration of initial and late phases of the AVREC (>3 SDs above baseline) were both prolonged by the application of SKF38393. $\boldsymbol{E}$, AVREC mean integral of initial (top) and late (bottom) phase (pale color), and by unbalanced current flow during each phase (dark color) originating from horizontal corticocortical input obtained from weighting the AVREC by the mean relative residuals (Happel et al., 2010).

the different tonotopic sites, so that conclusions drawn from this study seem to hold true at least for the main parts of the auditory cortex.

In the second part of the study, electrical stimuli were applied using two different spatial designs of stimulation arrays consisting of Tefloninsulated stainless steel wires ( $\varnothing$ with isolation $=50 \mu \mathrm{m}$, California Fine Wire) in another set of 12 animals. For stimulation in different cortical depths $(n=8)$, we implanted arrays of three electrodes, terminating at cortical depths of 100,600, and $1200 \mu \mathrm{m}$, respectively (Fig. 1C). For stimulation at variable distances from the recording site $(n=4)$, we implanted arrays of five electrodes, all terminating at a depth of $1200 \mu \mathrm{m}$ with $300 \mu \mathrm{m}$ horizontal interelectrode distance. Pseudorandomized series of biphasic cathodic-first single pulses $(80 \mu \mathrm{A})$ and a phase duration of $200 \mu$ s with a $50 \mu$ s interphase interval were digitally synthesized and controlled using MATLAB (MathWorks), and delivered via a multichannel stimulator (STG 2000, Multichannel Systems). The interstimulus interval in this part varied between 1.8 and $2.2 \mathrm{~s}$. After the experiments, we used strong monopolar (MP) cathodic current delivered through all stimulation channels to obtain iron deposits in the tissue at the position of implantation. Histological analysis of the recording electrode position relative to the cortical layers is explained below.

Pharmacological silencing of cortical activity. Intracortical activity was blocked in the electrical stimulation experiments by epidural application of the $\mathrm{GABA}_{\mathrm{A}}$ agonist muscimol hydrobromide (Sigma), $20 \mu \mathrm{l}$ muscimol alone with concentrations varied between 0.2 and $1.0 \mu \mathrm{g} / \mu \mathrm{l}(n=10)$ or concomitantly applied with $\mathrm{GABA}_{\mathrm{B}}$ receptor agonist (+)-5,5-dimethyl2-morpholine acetic acid (SCH50911; $6 \mathrm{~mm}, 20 \mu \mathrm{l}, n=2)$ to block $\mathrm{GABA}_{\mathrm{B}}$-mediated presynaptic inhibition of thalamocortical synapses by muscimol effects on $\mathrm{GABA}_{\mathrm{B}}$ receptors (Liu et al., 2007). We did not find any differences between these methods; for further information on the adequacy of different silencing techniques, see also Happel et al., 2010.

Current source density analysis. The one-dimensional CSD profile was derived from the second spatial LFP derivative, as follows:

$$
-\mathrm{CSD} \approx \frac{\delta^{2} \varphi(z)}{\delta z^{2}}=\frac{\varphi(z+n \Delta z)-2 \varphi(z)+\varphi(z-n \Delta z)}{(n \Delta z)^{2}},
$$

where $\Phi$ is the field potential, $z$ is the coordinate perpendicular to the cortical layers, $\Delta z$ is the sampling interval $(55-70 \mu \mathrm{m})$, and $n$ is the differentiation grid (Mitzdorf, 1985; Happel et al., 2010). LFP profiles were smoothed with a weighted average (Hamming window) across five channels (spatial filter kernel of $\sim 300 \mu \mathrm{m}$ ). To retain the upper and lower boundary sites, we used a linear extrapolation method that assumes no additional decay in the second derivative of the field potential (Happel et al., 2010).

CSD data analysis. For each animal and stimulus condition, onset latencies, peak amplitudes, and peak latencies were determined for the initial supragranular (SG), granular (G), and infragranular (IG) sinks from the CSD signals averaged across the channels within the layers 
corresponding to the sink. For analysis of tone-evoked sink components, we averaged those channels that displayed the shortest onset latencies of the early supragranular, granular, and infragranular sink, respectively (all channels with onset latencies $\leq 2 \mathrm{~ms}$ ( $\mathrm{G}$ sink) or $\leq 5 \mathrm{~ms}$ (SG and IG sinks) after the first tone-evoked onset activation). For ICMS-evoked responses, channels attributed to individual sink components were identical to laminar sink locations derived from previous pure-tone stimulation within the same recording session. The number of channels per individual sink component was kept constant when comparing responses in untreated cortex and after application of SKF38393, and were largely similar across animals (for $n=8$ recordings; channel numbers/ laminar extent contributing to $\mathrm{G} \operatorname{sink}(4.4 \pm 0.26 / 210 \pm 16 \mu \mathrm{m}), \mathrm{SG}$ sink $(3.4 \pm 0.32 / 147 \pm 20 \mu \mathrm{m})$, and IG sink $(3.5 \pm 0.42 / 155 \pm 26 \mu \mathrm{m})$; for representative example, see Fig. $1 A$, and for quantitative analysis, see Fig. $2 B$ ). All sink-based comparisons (see below) were made on the averaged traces representing the individual sink components defined by the channels exploiting the shortest onset latencies. Onset latencies of the sinks were defined as the crossing of a linear fit around the point where the initial deflection of the layer-specific CSD signals fell below 3 SDs of a 50 ms baseline before stimulus onset. The peak latencies of individual sinks were defined by the latency of first local minimum ( $\geq 5 \mathrm{~ms}$ duration) after sink onset. Peak amplitudes were defined as the highest amplitude of an individual sink. Sink mean amplitudes of auditory-evoked responses were calculated by averaging the sink amplitude in the interval between sink onset and peak.

The averaged rectified CSD (AVREC) was calculated by averaging the absolute values of the CSD separately across all of the $n$ channels for each trial, and averaging across trials afterward (Eq. 2). While information on the direction of transmembrane current flow is lost by rectification, the resulting AVREC waveform provides a measure of the temporal pattern of the overall strength of transmembrane current flow (Schroeder et al., 1998). The relative CSD residues were calculated as the sum of the CSDs over all of the $n$ channels divided by the sum of the respective absolute values (Eq. 3), as follows:

$$
\begin{aligned}
& \text { AVREC }=\frac{\sum_{i=1}^{n}\left|\operatorname{CSD}_{i}(t)\right|}{n} \\
& \text { relative residues }=\frac{\sum_{i=l}^{n} \operatorname{CSD}_{i}(t)}{\sum_{i=l}^{n}\left|\operatorname{CSD}_{i}(t)\right|} \text {. }
\end{aligned}
$$

Quantitative analysis of the AVREC and the relative residues was performed on single-trial CSD waveforms without spatial filtering. Onset latencies of AVREC and relative residues were defined as the time point when crossing $3 \mathrm{SDs}$ from baseline (based on $50 \mathrm{~ms}$ prestimulus period). Offsets of the initial phase were defined as the next crossing with the baseline or as the first inflection of the AVREC curve for at least $5 \mathrm{~ms}$. Offset of late phases was defined as the last crossing of 3 SDs from the baseline.

For auditory stimulation before and after administration of SKF38393, cross-correlation functions were calculated between granular and infragranular CSD time series (averaged traces of individual sink components used as above) in $25 \mathrm{~ms}$ time windows after the onset of the first sink. To keep the length of the correlated segments constant at $25 \mathrm{~ms}$, signal segments to be correlated were selected from signal intervals shifted in steps of $0.5 \mathrm{~ms}$ within a range of $\pm 40 \mathrm{~ms}$. Signal energies for normalization were determined separately for every single time lag. Correlation coefficients at each lag were averaged across subjects using Fisher's $z$-transform (Deliano et al., 2009).

Histochemistry and histology. Following acute experiments, animals were killed by intracardial injection of $0.5 \mathrm{ml} \mathrm{T61}$ (Intervet), and brains were removed immediately and cut on a cryostat microtome into $50 \mu \mathrm{m}$ horizontal sections $(n=5)$. Cortical layers have been identified on the basis of Nissl stains according to previous anatomical studies (Budinger et al., 2006), and the locations of the stimulation channels have been analyzed using Prussian blue staining, which makes evoked iron deposition visible by long monophasic currents after the experiments (Fig. 1C). Recently, we have described the average thickness of the cortical layers in the primary auditory cortex in the Mongolian gerbil (Happel et al., 2010) and chose the stimulation depths of layer-dependent ICMS corresponding to this. A cortical depth of $100 \mu \mathrm{m}$ corresponds to the border between layers I and II, $600 \mu \mathrm{m}$ to layers III and IV, and $1200 \mu \mathrm{m}$ to layers V and VI (Fig. 1C).

Behavioral training and stimulation. In a third part of the study, we trained another set of animals in a shuttlebox placed in an acoustically and electrically shielded chamber in a detection task $(n=10)$. Intracortically applied electrical stimuli delivered to the supragranular, granular, and infragranular electrode by a multichannel stimulator (STG 2000, Multichannel Systems) were used as conditioned stimuli, and consisted of trains [300 ms length, 100 pulses/s (pps)] of biphasic, charge-balanced pulses (cathodic first) with $200 \mu$ s phase duration. Trains were repeated with a pause of $700 \mathrm{~ms}$ for a maximum duration of $4 \mathrm{~s}$. A mild footshock [unconditioned stimulus (US)] was delivered through the grid floor (200-600 mA) $4 \mathrm{~s}$ after the conditioned stimulus (CS) onset unless the animal changed its compartment (Deliano et al., 2009). The US lasted for $6 \mathrm{~s}$ but could be terminated together with CS by the animal through a compartment change. For the detection task, intertrial intervals varied randomly between 15 and $19 \mathrm{~s}$. Before the start of each session, all animals were allowed to explore the shuttlebox for $3 \mathrm{~min}$ to adapt to the environment. Training and testing of stimulus parameter variations was performed in three blocks with different stimuli. In a first block of initial avoidance learning (sessions 1-12), monopolar electrical stimuli, as the CSs, were applied with a current amplitude of $80 \mu \mathrm{A}$ (Deliano et al., 2009) to supragranular, granular, and infragranular electrodes in pseudorandomized order across the 60 trials (20 trials per stimulation depth) of a session. In a second block of eight to nine test sessions (84-108 trials per session) after all animals had acquired stable detection performance, the current strength was varied to assess detection performance as a function of stimulus amplitude. For each stimulation depth, 14-18 trials were gathered for each of 11 levels of stimulus strength ranging between 5 and $100 \mu \mathrm{A}(5,7,15,20,30,40,50,60,70,80$, and $100 \mu \mathrm{A})$. In a third block of eight behavioral testing sessions ( 96 trials per session), stimulation was switched to a bipolar mode. Supragranular and infragranular electrodes were paired with the granular electrode, respectively. Depending on the polarity of the applied currents, this resulted in four different bipolar stimulation configurations (see Fig. 7D). For each of these configurations, $12-18$ trials were obtained for eight stimulus levels in a range between 5 and $100 \mu \mathrm{A}(5,10,20,30,40,60,80$, and $100 \mu \mathrm{A})$, respectively. In both test blocks, each level was tested in two to three different sessions at each monopolar stimulation depth, and with each bipolar configuration presented in a pseudorandomized order across trials and sessions. To avoid extinction learning, a stimulus level of at least $60 \mu \mathrm{A}$ was included in each of the sessions at all conditions. In a subset of animals $(n=5)$, blank trials without CSs and USs were interspersed between the test trials.

Analysis of behavioral data. In every animal, separately for each monopolar depth and bipolar configuration, conditioned response rates were obtained for each stimulus strength from trials pooled across all sessions in which this stimulus strength was presented. To quantify detection sensitivity $\left(d^{\prime}\right)$ independent of experimental conditions biasing the response of the animal (Deliano et al., 2009), $d^{\prime}$ values derived from signal detection theory were calculated from the conditioned response rates (hit rates) and false-alarm rates estimated for each session from pre-CS intervals of the same length as the CS-US interval (4 s). False-alarm rates corresponding to the hit rate of a stimulus condition were obtained by averaging across sessions in which the stimulus condition was applied. False-alarm rates determined this way did not differ significantly from false-alarm rates obtained from blank trials in a subset of animals $(n=5$; Wilcoxon signed rank test, $p=0.13$ ). The $z$-scores of corresponding hit and false-alarm rates were derived from the inverses of a standardized normal distribution function, respectively, and $d^{\prime}$ values were calculated by subtracting these $z$-scores. 
For psychometric analysis, $d^{\prime}$ was analyzed as a function of stimulus strength, separately for each ICMS configuration. A threshold criterion for stimulus detection of $d^{\prime}=1.0$ was applied, which corresponds to a signal strength of 1 SD above noise. Thresholds were obtained in single animals for each depth for monopolar stimulation and for each bipolar configuration. To remove fluctuations around the defined threshold, response curves were slightly smoothed by a weighted averaging of $k d^{\prime}$ values across neighboring levels of stimulus strength $(k=2$ for lowest and highest level, and $k=3$ for levels in between). Thereby, the weighting was proportional to the difference between the neighboring levels, with a factor of $1 / 3$ at a difference of $20 \mu \mathrm{A}$. Stimulus strength at the threshold criterion of $d^{\prime}=1.0$ was then determined by linear interpolation between the first $d^{\prime}$ value above threshold and the preceding value below threshold.

Statistical analysis. For statistical comparison between two groups, we used paired-sample Student's $t$ tests. Comparison of multiple groups was performed by multifactorial repeated-measures ANOVAs (rmANOVAs; with Huynh-Feldt correction of sphericity) using SPSS version 8.0. For post hoc tests, we used restricted two-way rmANOVAs or paired-sample Student's $t$ tests. Generally, a significance level of $\alpha^{*}=0.05$ was chosen or a Bonferroni-corrected levels of significance in case of testing repeatedly for $n_{\text {test }}$ times $\left(\alpha^{*}=\alpha / n_{\text {test }}\right)$.

\section{Results}

Dopaminergic neurotransmission in sensory cortex enhances local activity in corticoefferent layers and strengthens corticocortical interactions

Using CSD analysis in primary auditory cortex of anesthetized Mongolian gerbils $(n=8)$, we investigated the laminar organization of extracellular synaptic current flow in response to acoustic stimulation with the best frequency at the recording site, before and after subcutaneous injection of $D_{1} / D_{5}$ receptor agonist SKF38393 (5 mg/100 g body weight; Schicknick et al., 2008). In untreated AI, best-frequency stimulation evoked a typical cascade of current sinks across layers with initial synaptic input in the G layers followed by SG and IG layers, reflecting the activation of local cortical microcircuits (Schroeder et al., 1998; Sakata and Harris, 2009; Happel et al., 2010; Fig. 2A, left). In most cases, we found an additional short-latent input to layer V/VI, which has been demonstrated before and after cortical silencing with muscimol (Happel et al., 2010), and hence reflects separate thalamocortical input to deeper layers by collaterals of afferent axons described in several anatomical studies (Winer et al., 2005; Budinger et al., 2006) and physiological studies (Müller-Preuss and Mitzdorf, 1984; Szymanski et al., 2009). SKF38393 administration significantly enhanced early IG activity relative to initial G and SG activation (Fig. $2 A$, right), leading to a qualitative change in the cross-laminar response profile now characterized by strong concomitant early activity in granular and infragranular layers when comparing sink mean amplitudes in the interval from sink onset to peak latency (Fig. 2C; rmANOVA, $\alpha^{*}=0.05$, significant main effect of factor "layer," and significant interaction between factors "layer $\times$ treatment"; Table 1, 1.1). To control for the stable position of the recording electrode and the respective sink components throughout individual experiments, we subsequently applied the $\mathrm{D}_{1} / \mathrm{D}_{5}$ antagonist $\mathrm{SCH} 23390$ to reverse the effect of the $D_{1} / D_{5}$ agonist. The laminar extent of the $S G, G$, and IG sinks is shown together with the CSD channels displaying the shortest onset latencies chosen for averaging (Fig. 2B; see Materials and Methods). Laminar depths of sinks and chosen channels for averaging remained stable over the course of the complete experiment (paired-sample Students's $t$ test, $p>0.05$ ). The significant increase in spatial extent of the IG sink after application of SKF38393 $(p=0.005)$ was reversed by the antagonist $\mathrm{SCH} 23390(p>0.05)$.
Total synaptic current flow before and after SKF38393 application was quantified by the AVREC (Fig. 2D; see Schroeder et al., 1998). Further, the relative residuum of the CSD was used to quantify the ratio of unbalanced current sinks and sources (see Materials and Methods). The CSD residuum allows for assessing the contribution of distal horizontal synaptic inputs oriented perpendicular to the recording axis, as they are reaching beyond the cylinder around the recording axis in which radial currents influence the LFP measured by the recording electrode. As previously shown, the CSD residuum is a suitable measure of the recruitment of intracortically relayed horizontal synaptic input (Happel et al., 2010). SKF38393 significantly increased the initial phase of the AVREC time course (measured from onset to first offset or point of inflection; Fig. $2 D$, top; paired-sample Student's $t$ test, $p=0.004)$ without increasing the CSD residuum ( $p=$ 0.35 ). During later phases of cortical activation (measured from end of initial phase to offset), the total current source density, as measured by the AVREC (Fig. 2E, bottom), was increased ( $p<$ $0.001)$ and accompanied by an increased CSD residuum ( $p=$ 0.002 ). Hence, the administration of SKF38393 changed the laminar activation profile qualitatively and increased the total amount of initial synaptic current flow by prolonging local, intracolumnar cortical inputs and subsequently prolonged and strengthened longer-latent horizontal corticocortical interactions during later phases of processing. Sink onset latencies did not differ between granular and infragranular layers, or before and after the administration of SKF38393 (mean onset latency, $8.9 \pm 0.5 \mathrm{~ms}$; two-way rmANOVA, $\alpha^{*}=0.05$; no significant main effects or interactions of factors layer and "treatment"; Table 1, 1.2). Apparently, initial cortical activation via thalamocortical input to granular layers and collateral parallel input to infragranular layers was unaffected by $D_{1} / D_{5}$ receptor manipulation.

The first insight into the circuit mechanisms underlying the described effects of the $D_{1} / D_{5}$ agonist in AI came from the analysis of the temporal organization of the different laminar sinks. The peak latency of the granular sink was prolonged by $D_{1} / D_{5}$ modulation, whereas the infragranular peak latency under SKF38393 did not differ from the granular and infragranular peak latencies in untreated AI (Fig. $3 A, B$; two-way rmANOVA, $\alpha^{\star}=0.05$; significant main effect of factor layer and significant interaction of factors layer $\times$ treatment; Table $1,1.3)$. When subtracting the peak latency of the infragranular sink from the granular sink, this peak latency difference significantly increased from $1.8 \pm 1.0$ to $6.4 \pm 2.0 \mathrm{~ms}$ with SKF38393 treatment (pairedsample Student's $t$ test, $p=0.039$ ). SKF38393 administration did not change granular onset latency but prolonged the time until peak activation was reached. Such a prolonged rise of sink activity would be compatible with a delayed positive feedback activation of granular input layers. To demonstrate this feedback, we performed a time-lagged cross-correlation analysis of the first $25 \mathrm{~ms}$ after cortical activity onset (see Materials and Methods), which showed that dopaminergic stimulation significantly increased the correlation between initial granular and infragranular activation, and shifted the peak of the correlogram from a granular lag of $2.5 \mathrm{~ms}(95 \% \mathrm{CI} \pm 0.34)$ to $5.5 \mathrm{~ms}(95 \% \mathrm{CI} \pm 0.78$; Fig. $3 C$; paired-sample Student's $t$ test, $p=0.038)$.

Together, these findings demonstrate that dopamine affects the cortical processing scheme, with its known laminar and temporal organization. The increased correlation at a relative synaptic delay of $\sim 6 \mathrm{~ms}$ provides a first indication of a positive feedback routed from deeper cortical layers back to cortical input layers. Given that $D_{1} / D_{5}$ receptors are predominantly located in 
Table 1. Statistical analysis of CSD sink and behavioral data by repeated-measures ANOVA

Factor

\section{Layer}

Treatment

Layer $\times$ treatment

(1.2) SKF38393 effects on onset latencies of granular and infragranular sink (two-way rmANOVA; $\alpha^{*}=0.05$ )

Layer

Treatment

Layer $\times$ treatment

(1.3) SKF38393 effects on peak latencies of granular and infragranular sink (two-way rmANOVA; $\alpha^{*}=0.05$ )

Layer

Treatment

Layer $\times$ treatment

(1.4) Onset latencies after proximal ICMS before cortical silencing (two-way rmANOVA; $\alpha^{*}=0.025$ )

Layer

Stimulation-depth

Stimulation-depth $\times$ layer

(1.5) Onset latencies after distal ICMS before cortical silencing (two-way rmANOVA; $\alpha^{*}=0.025$ )

Layer

Stimulation-depth

Stimulation-depth $\times$ layer

(1.6) Peak amplitudes after proximal ICMS (3-way rmANOVA; $\alpha^{*}=0.025$ )

Layer

Stimulation-depth

Stimulation-depth $\times$ layer

Silencing

Layer $\times$ silencing

Stimulation-depth $\times$ silencing

Layer $\times$ stimulation-depth $\times$ silencing

(1.7) Peak amplitudes after distal ICMS (three-way rmANOVA; $\alpha^{*}=0.025$ )

Layer

Stimulation-depth

Stimulation-depth $\times$ layer

Silencing

Layer $\times$ silencing

Stimulation-depth $\times$ silencing

Layer $\times$ stimulation-depth $\times$ silencing

(1.8) Post hoc test for granular peak amplitudes after proximal ICMS (two-way rmANOVA $\alpha^{*}=0.0056$ )

Stimulation-depth

Silencing

Stimulation-depth $\times$ silencing

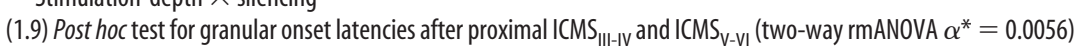

Stimulation-depth

Silencing

Stimulation-depth $\times$ silencing

(1.10) Layer symmetry index of peak amplitudes (two-way rmANOVA; $\alpha^{*}=0.025$ )

Stimulation-depth

Distance

Stimulation-depth $\times$ distance

(1.11) Normalized peak amplitude- distance functions of granular activation before and after silencing (two-way rmANOVA; $\alpha^{*}=0.05$ )

Silencing

Distance

Silencing $\times$ distance

(1.12) Normalized peak amplitude-distance function between granular sink $\mathrm{G}$ (after silencing) and infragranular sink IG (untreated) (two-way rmANOVA; $\alpha^{*}=0.05$ )

$\mathrm{G} / \mathrm{IG}$

Distance

$\mathrm{G} / \mathrm{IG} \times$ distance

(1.13) Monopolar psychometric functions (two-way rmANOVA; $\alpha^{*}=0.05$ )

Stimulation amplitude

Stimulation depth

Stimulation-amplitude $\times$ stimulation-depth

(1.14) Bipolar psychometric functions (two-way rmANOVA; $\alpha^{*}=0.05$ )

Stimulation amplitude

BP-ICMS configuration

Stimulation-amplitude $\times$ ICMS-configuration
Fvalue

$p$ value

$F_{(2,30)}=55$

$F_{(1,15)}=0.27$

$F_{(2,30)}=72.6$

$<0.001$

0.611

$<0.001$

$F_{(1,7)}=0.08$

0.980

$F_{(1,7)}=0.78$

0.981

$F_{(1,7)}=18.75$

0.188

$F_{(1,7)}=136.13$

0.016

$F_{(1,7)}=47.53$

0.390

$F_{(1,7)}=40.5$

0.042

$F_{(2,14)}=50.2$

$F_{(2,14)}=21.2$

$<0.001$

0.010

$F_{(4,28)}=5.28$

0.037

$F_{(1.67,11.70)}=58.91$

$F_{(2,14)}=1.54$

$<0.001$

$F_{(4,28)}=2.05$

0.248

$F_{(2,8.19)}=48.1$

$F_{(1.41,9.89)}=33$

$F_{(4,28)}=8.34$

$F_{(1,7)}=198.10$

$F_{(2,14)}=7.47$

$F_{(2,14)}=205$

$F_{(2,1.2}=14.3$

$F_{(2,14)}=12.5$

$F_{(2,10)}=114$

$F_{(2.58,18.08)}=1.17$

$F_{(1,7)}=103.44$

$F_{(2,14)}=4.53$

$F_{(4,28)}=1.13$

$F_{(2.52,17.62)}=1.64$

0.183

$<0.001$

$<0.001$

0.003

$<0.001$

0.006

0.009

$<0.001$

$<0.001$

$<0.001$

0.35

$<0.001$

0.071

0.350

0.224

$F_{(1,7)}=12$

$F_{(1,)}=97.4$

$F_{(1,7)}=20.2$

0.009

$<0.001$

0.002

$F_{(1,8)}=4.06$

$F_{(1,8)}=10.84$

$F_{(1,8)}=27.91$

0.079

0.011

$<0.001$

$F_{(2,14)}=11.1$

$F_{(1,7)}=35.1$

$F_{(2,14)}=32.2$

0.001

$>0.001$

0.005

$F_{(4,20)}=3.07$

$F_{(4,24)}=10.5$

$F_{(4,20)}=12.31$

0.140

$<0.001$

0.004

$F_{(1,5)}=3.07$

$F_{(4,20)}=30.38$

0.140

$F_{(4,20)}=0.31$

$<0.001$

0.698

$F_{(7.07,63.63)}=24.08$

$<0.001$

$F_{(1.58,14.18)}=26.98$

$<0.001$

$F_{(15.04,135.36)}=5.57$

$<0.001$

$F_{(7,63)}=30.76$

$<0.001$

$F_{(2.53,22.74)}=41.05$

$F_{(17.12,154.08)}=21.10$
$<0.001$

0.009 


\begin{tabular}{ll}
\hline Factor & $F$ value \\
\hline (1.15) Reaction times after monopolar ICMS (two-way rmANOVA; $\left.\alpha^{*}=0.05\right)$ & \\
$\quad$ Stimulation depth & $F_{(0.6,2)}=18$ \\
Stimulation amplitude & $F_{(0.6,11)}=26.98$ \\
Stimulation depth $\times$ stimulation-amplitude & $F_{(1.2,2)}=198$ \\
(1.16) Reaction times after bipolar ISMC (two-way rmANOVA; $\left.\alpha^{*}=0.05\right)$ & $F_{(1.3,3)}=27$ \\
BP-ICMS configuration & $F_{(1,7)}=41.05$ \\
Stimulation amplitude & $F_{(17.12,154.08)}=21.10$ \\
Stimulation-amplitude $\times$ ICMS-configuration & 0.33 \\
\hline
\end{tabular}

All rmANOVAs were Huyn-Feldt corrected and based on a significance level of $\alpha^{*}=0.05$ or on Bonferroni-corrected levels of significance, as indicated.

infragranular output layers (Campbell et al., 1987; Phillipson et al., 1987; Krimer et al., 1997; Schicknick et al., 2008), and that local intracortical routing of recurrent microcircuits in AI (Liu et al., 2007) is characterized by shorter synaptic delays of 0.8-1.0 ms per cortical synapse (Tsumoto and Suda, 1982), these findings are compatible with a polysynaptic routing of the feedback via relays outside the analyzed cortical area. The following sections describe a stepwise procedure to find support for this hypothesis and rule out alternative interpretations on a cortical circuit level.

\section{Proximal (but not distal) ICMS in infragranular (but not granular or supragranular) layers mimics SKF38393-induced cortical cross- laminar activation patterns} Based on the above described results, in the next experiment a more detailed circuit analysis was performed by combining intracortical microstimulation $(n=12$; $\pm 80 \mu \mathrm{A}$; bipolar cathodic-first, $100 \mu \mathrm{s}$ phase duration, $50 \mu$ s interphase interval) with CSD analysis. We applied ICMS to supragranular layers I-II $\left(\mathrm{ICMS}_{\text {I-II }} ; 100\right.$ $\mu \mathrm{m}$ cortical depth), to granular layers

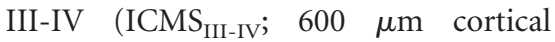
depth), and to infragranular layers V-VI $\left(\right.$ ICMS $_{\mathrm{V}-\mathrm{VI}} ; 1200 \mu \mathrm{m}$ cortical depth), to differentially activate corticoafferent, corticocortical, and corticoefferent parts of the cortical circuitry. For histological verification of the stimulation sites, see Figure $1 C$ and Materials and Methods. Layer-specific ICMS was applied at lateral distances of either $300 \mu \mathrm{m}$ (proximal, $n=4$ ) or $1200 \mu \mathrm{m}$ (distal, $n=4$ ) from the recording site, in two separate groups of animals.

Except for proximal supragranular ICMS, evoked CSD patterns in AI displayed a spatiotemporal activation profile with initial G and subsequent SG and IG synaptic input similar to the patterns found with auditory stimulation (Schroeder et al., 1998; Sakata and Harris, 2009; Happel et al., 2010; Figs. 2A, 4). Granular sink activation generally had the shortest onset latency (Fig. $5 A, B$, right), which was statistically confirmed by significant main effects of factor layer (SG, G, and IG) after both proximal and distal ICMS (rmANOVAs, Bonferroni corrected, $\alpha^{*}=0.025$; Table 1, 1.4 and 1.5). Only after proximal, supragranular ICMS, earliest activation was also found in supragranular layers addi- tionally yielding a significant effect of factor "stimulation depth" ICMS $_{\text {I-II }}$ ICMS ditions, highest peak amplitudes were evoked by proximal infragranular ICMS, concomitantly in G and IG layers (Figs. 4A, left, $5 A$, left). Proximal granular ICMS yielded lower granular and infragranular amplitudes, but the strongest supragranular activation. Supragranular ICMS proximally evoked the smallest amplitudes throughout all layers without any sign of cross-laminar activity spread (Fig. 4A, left; Happel et al., 2010). Accordingly, after proximal ICMS significant amplitude differences (Fig. 5A, left) were found with respect to factors layer and stimulation depth, and their interaction (rmANOVA, $\alpha^{\star}=0.025$; Table 1, 1.6).

ICMS also activated distal cortical microcircuits over distances of $1200 \mu \mathrm{m}$ (Fig. 4B, left). In contrast to proximal stimulation, the highest peak amplitudes at distal sites were evoked by granular ICMS (Fig. 5B, left), and activation was always strongest in granular layers, independent of stimulation depth (significant main effects for factors layer and stimulation depth, but no significant interaction; rmANOVA, $\alpha^{\star}=0.025$; Table 1, 1.7; for post hoc rmANOVAs, see Table 1, 1.8 and 1.9). 

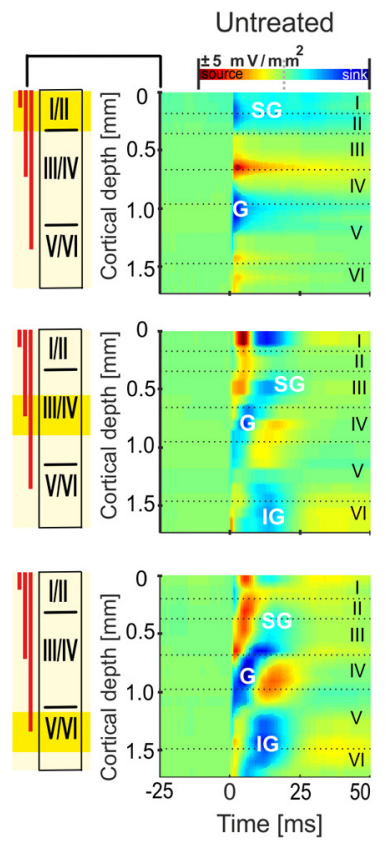

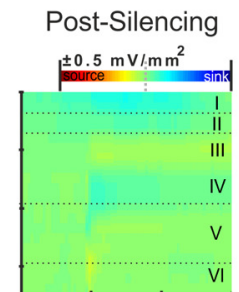

\section{B Distal stimulation $(1200 \mu \mathrm{m})$}
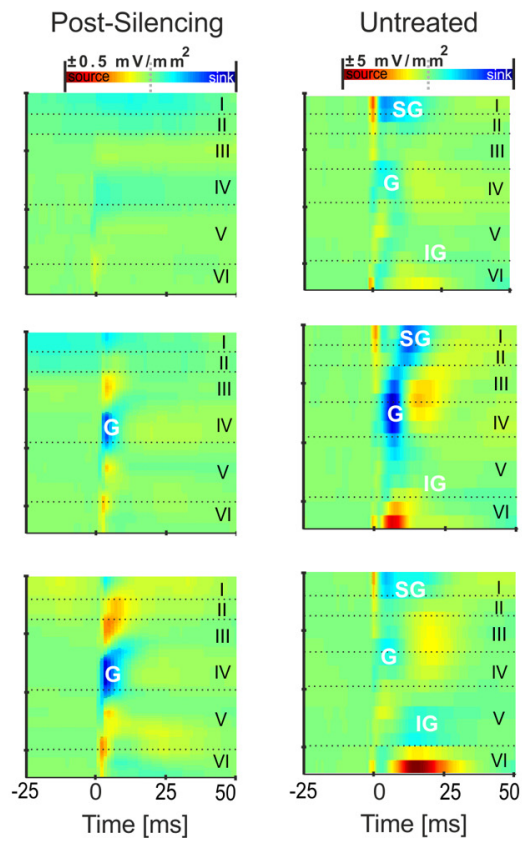
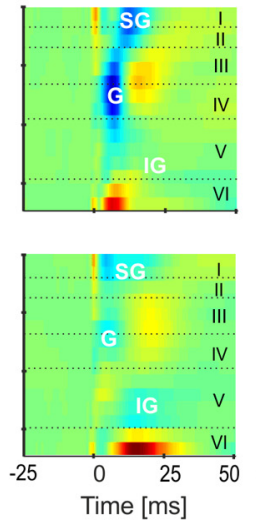

Figure 4. Dissociation of local intracortical polysynaptic and thalamocortical monosynaptic inputs during layer-specific ICMS. $\boldsymbol{A}$, Left, In proximal distance to the stimulation site $(300 \mu \mathrm{m})$, granular (III/IV) and infragranular (V/VI) ICMS evoked CSD profiles with a canonical cross-laminar pattern of activation comparable to auditory stimulation ( $G$ sink followed by subsequent extragranular IG and SG sinks). Supragranular ICMS (I/II) did not evoke cross-laminar interactions. Right, During cortical silencing, stimulation of both infragranular and granular layers mainly activated input layer IV (CSD amplitude reduction to $10-30 \%$ of original values; compare with color bar scaling; Fig. 5A). During supragranular stimulation, evoked activity was completely abolished by silencing. $B$, Long-distance polysynaptic activations during distal ICMS led to a similar cascade of cross-laminar activations at distal cortical sites regardless of stimulation depth. Nevertheless, granular ICMS evoked the strongest network activations compared with supragranular and infragranular ICMS. Right, Cortical silencing revealed that distal activations of local microcircuits were transmitted almost exclusively via polysynaptic horizontal intracortical pathways, most effectively when stimulating cortical input layers. Stimulation electrodes (red lines) and stimulation depth (yellow square) are schematically indicated on the left.

Cross-laminar activation patterns were quantified and statistically analyzed by introducing a layer symmetry index (LSI; Fig. 5C). The LSI of ICMS-evoked responses showed a significant interaction of factors stimulation depth and "distance" (rmANOVA; $\alpha^{*}=0.025$; Table $\left.1,1.10\right)$. Thus, only proximal infragranular ICMS yielded a distinct asymmetric cross-laminar activation pattern with strong concomitant recruitment of granular and infragranular layers (Fig. $5 A, C$ ), as found after auditory stimulation under enhanced dopaminergic neuromodulation (Fig. 5C). All other activations were symmetric and dominated by granular layers, as with auditory responses in untreated cortex.

\section{Differential excitation of corticoefferent feedback and corticocortical feedforward pathways by layer-specific ICMS} Symmetric and asymmetric cross-laminar activation patterns could arise from layer-dependent excitation of several candidate neuronal pathways, including corticoafferent, corticocortical, or recurrent corticoefferent pathways (see Discussion). To disentangle these pathways, monosynaptic inputs were isolated in the next step of the analysis by silencing polysynaptic corticocortical activations through topical application of the $\mathrm{GABA}_{\mathrm{A}}$ agonist muscimol (4 mM, $20 \mu$ l; Happel et al., 2010). Cortical silencing suppressed ICMS-evoked cross-laminar processing. However, a granular sink persisted after proximal granular and infragranular ICMS (Fig. $4 A$, right). Although the amplitude of the persistent sink was reduced, it largely overlapped in time and depth profile with the

\section{Post-Silencing}
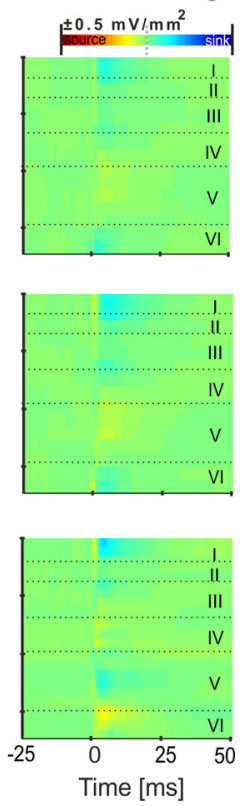

G sink in untreated cortex (Figs. 4, 5A). Obviously, granular input in untreated cortex was strongly amplified by polysynaptic intracortical interactions, most likely by the local recurrent excitatory microcircuitry (Liu et al., 2007; Happel et al., 2010). Persistent granular input was found exclusively after proximal granular and infragranular ICMS, consistent with significant effects of factor "silencing" on peak amplitudes evoked by proximal and distal ICMS and significant interactions with factors layer and stimulation depth, and significant three-way interaction between all factors only found after proximal ICMS (rmANOVA, $\alpha^{*}=0.025$; Table 1, 1.6 and 1.7).

Due to the suppressed intracortically relayed polysynaptic signal transmission, the persisting granular sink after silencing in response to proximal ICMS reflects a monosynaptic activation of granular layers. In principle, such an activation could stem from the direct excitation of corticocortical or corticoafferent fibers that bypass the stimulation site and terminate in granular layers. Alternatively, the persisting granular sink could originate from an excitation of corticoefferent fibers routed back to granular layers via synaptic relays outside the silenced cortical area. In combination with direct microstimulation, intracortical silencing allowed us to isolate extracortical inputs from many other intracortical processes. Therefore, onset latency measurements provide the strongest evidence for the circuit origin of the persisting input. Whereas the mean ( \pm SEM) onset latency of the persisting granular sink after silencing did not change in response to infragranular ICMS (before, $5.85 \pm 0.48 \mathrm{~ms}$; after, $6.56 \pm 1.39 \mathrm{~ms}$; Fig. $5 \mathrm{~A}$, right), it increased in response to granular ICMS (before, $2.13 \pm$ $0.63 \mathrm{~ms}$; after, $6.25 \pm 1.55 \mathrm{~ms}$; Fig. $5 \mathrm{~A}$, right), yielding values not significantly different from infragranular ICMS [significant interaction between factors stimulation depth ICMS $_{\text {III-IV }}$ and $\mathrm{ICMS}_{\mathrm{V} \text {-VI }}$ ) and silencing, $\alpha^{*}=0.056$; Table 1, 1.9]. Direct, monosynaptic activation with onset latencies of $>6 \mathrm{~ms}$ via orthodromically or antidromically excited corticoafferent or corticocortical fibers at proximal sites is very unlikely, due to the known conductance velocities $(0.3-5 \mathrm{~mm} / \mathrm{ms})$ and synaptic transmission delays in the cortex (Tsumoto and Suda, 1982). Onset latencies of $\sim 6$ $\mathrm{ms}$, therefore, strongly suggest that the residual sink activation after silencing relies on polysynaptic transmission, which under muscimol can only be routed via synaptic relays outside the suppressed AI, although in the untreated cortex the shorter onset latency of $\sim 2 \mathrm{~ms}$ with proximal granular ICMS indicates an additional, more direct, polysynaptic activation of granular layers via local corticoafferent or corticocortical fibers. However, the peak amplitude of the persistent granular sink was larger after infragranular than after granular proximal ICMS (significant interaction between factors silencing and stimulation depth in post hoc two-way rmANOVA; $\alpha^{\star}=0.056$; Table $1,1.8$ ), which is consistent with a granular activation originating from the excitation of infragranular corticoefferent fibers. Obviously, increased 
A

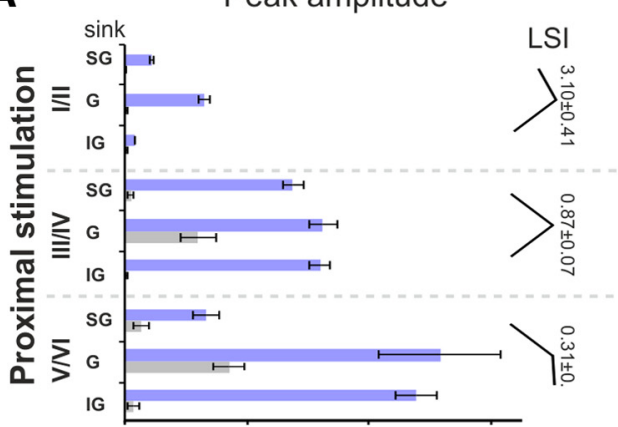

B

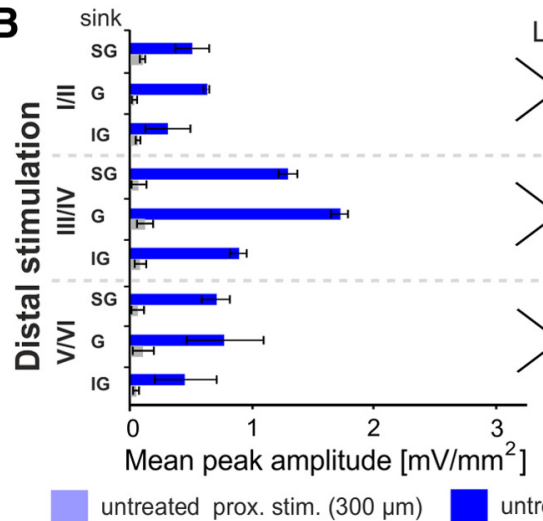<smiles>C[As]1(C)C[Si]1</smiles>

Onset latency

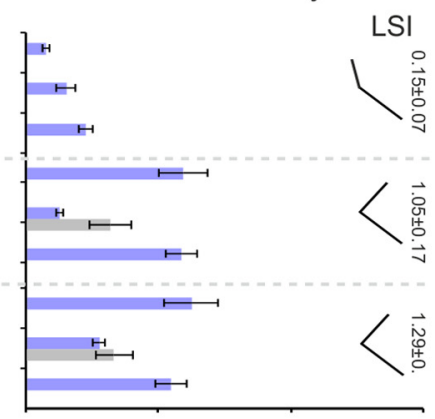

LSI

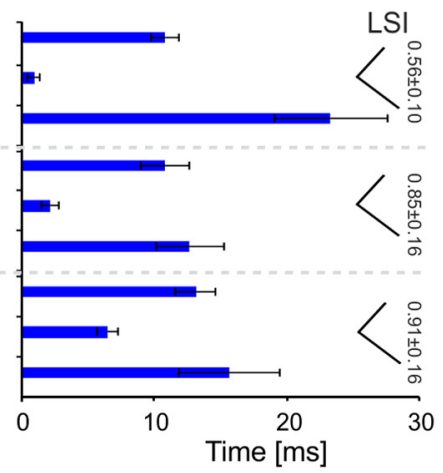

ntreated dist. stim. $(1200 \mu \mathrm{m})$

C

Layer-Symmetry-Index

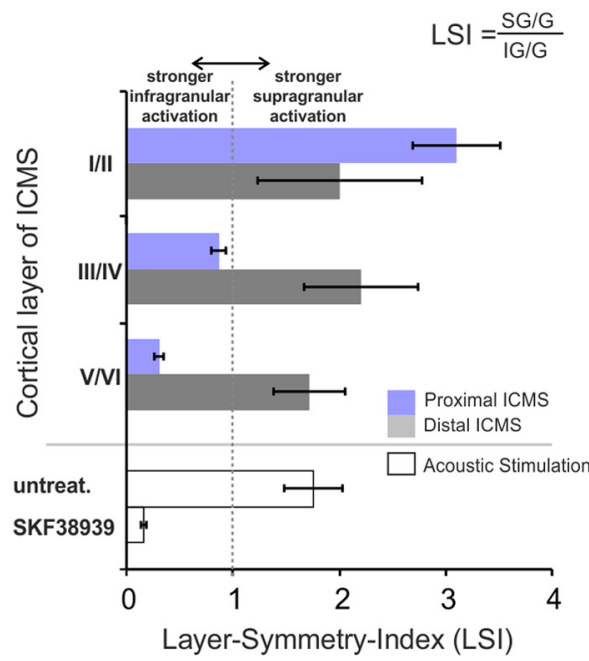

Figure 5. Comparison of laminar CSD responses. Mean ( \pm SEM) peak amplitudes and onset latencies of $S G, G$, and IG sinks evoked by proximal stimulation (prox. stim.; $A$ ) or distal stimulation (dist. stim.; $\boldsymbol{B}$ ) in SG (I/II), G (III/IV), or IG (V/VI) layers are shown before (blue) and after (gray) cortical silencing across animals. A, Proximal stimulation elicited the strongest amplitudes in stimulated layers and a decreased activation of granular layers during granular and infragranular ICMS after cortical silencing. $\boldsymbol{B}$, Mean peak amplitudes during distal stimulation showed similar symmetric relative amplitude and latency ratios (see insets depicting the corresponding $\mathrm{LSIs}$; see $\boldsymbol{C}$ ) regardless of stimulation depth. Cortical silencing abolished all distal network activations. $\boldsymbol{C}$, Quantification of relative cross-laminar activation patterns by an $L S I$ computed by $L S I=(S G / G) /(I G / G)$ for estimating the extragranular activations in relation to the activation of the granular layers independent from the absolute amplitude values. Top, The LSI revealed that the relative activation strength between layers depended only on the stimulation depth proximal to the stimulation site, with a gradual shift of activation toward the stimulated layers $(\mathrm{LSII} / \mathrm{II}=3.10 \pm 0.42 ; \mathrm{LSIIII/IV}=1.19 \pm 0.08 ; \mathrm{LSIV} / \mathrm{VI}=3.87 \pm 0.59)$. At distal sites laminar activation was independent from stimulation depth $(L S I I / I I=2.01 \pm 0.77 ; L S I I I I / I V=2.20 \pm 0.54 ; L S I ~ V / V I=1.72 \pm 0.34)$. See Table 1, 1.8, for statistical results. Auditory evoked cross-laminar profiles in untreated cortex (bottom) were comparable to the profiles after distal ICMS and showed stronger supragranular compared with infragranular responses $(1.76 \pm 0.16)$, while dopaminergic neurotransmission strongly shifted cortical activation toward deeper corticoefferent layers (LSI $=0.27 \pm 0.03$; paired-sample Student's $t$ test, $p<0.001)$.

activation of infragranular output, either by infragranular ICMS or by $\mathrm{D}_{1} / \mathrm{D}_{5}$ modulation of infragranular layers during auditory stimulation, leads to a positive feedback activation of granular layers at a delay of $\sim 6 \mathrm{~ms}$, as demonstrated by the $\sim 6 \mathrm{~ms}$ onset latency of the persistent granular sink after cortical silencing in response to ICMS, and by the peak in the cross-correlogram between granular and infragranular activation at a granular lag of $5.5 \mathrm{~ms}$ in response to auditory stimulation under SKF38393.

Focal recurrent corticoefferent feedback along the tonotopic axis relayed via first-order thalamocortical relays

Up to this point of the stepwise analysis, we have demonstrated a local dopamine-sensitive polysynaptic feedback pathway originating from infragranular corticoefferent fibers, and terminating in granular input layers effectively prolonging later corticocortical long-range interactions. Prolongation of the granular onset latency ( $\sim 6 \mathrm{~ms}$ ) during infragranular ICMS and cortical silencing revealed that this feedback was routed polysynaptically via extracortical relays. A likely candidate for such a relay is the thalamus, which is activated by infragranular corticoefferent output, and could provide recurrent first-order thalamocortical input to granular layers (Winer et al., 2005; Budinger et al., 2006; Kawai et al., 2007; Happel et al., 2010).

To assess a possible first-order thalamocortical routing of recurrent granular activation, distances between stimulation and recording sites $\left(\mathrm{ICMS}_{\mathrm{V}-\mathrm{VI}}\right.$ ) were systematically varied from 300 to $1500 \mu \mathrm{m}$ in $300 \mu \mathrm{m}$ steps along the rostrocaudal tonotopic axis $(n=4)$. After cortical silencing, granular activation persisted only at proximal stimulation sites (Fig. 6A, bottom; 300-600 $\mu \mathrm{m})$. Accordingly, granular sink amplitudes, normalized to their maximum in each condition, were similar up to a distance of $\sim 600 \mu \mathrm{m}$ but then decayed significantly faster after silencing (Fig. 6B, significant interaction between factors silencing and distance; two-way rmANOVA, $\alpha^{\star}=0.05$; Table 1, 1.11). With acoustic stimulation, granular activity after cortical silencing has been assigned to the focal, first-order, afferent input projection from the lemniscal medial geniculate body in a range of approximately \pm 1.5 octaves around the best frequency (Happel et al., 2010 ). With a cortical frequency resolution of $\sim 0.4 \mathrm{~mm}$ per octave (Scheich et al., 1993; Ohl et al., 2000), this corresponds to a cortical distance of $\sim 0.6 \mathrm{~mm}$, which is consistent with the observed lateral extent of the electrically evoked persistent granular sink (Fig. 6B). Moreover, no significant difference was found between the normalized amplitude-distance functions of the persistent $G$ sink after cortical silencing and the IG sink in untreated cortex (Fig. 6B; rmANOVA, $\alpha^{*}=0.05$; Table 1, 1.12). Thus, focal granular input after silencing and infragranular activation along the tonotopic axis were in exact spatial register within the tonotopic gradient of A1. This supports our previously stated hypothesis of a closed-loop positive feedback between granular and 
A
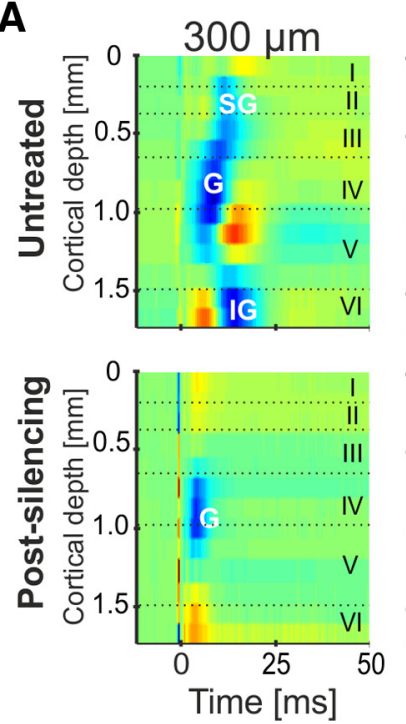
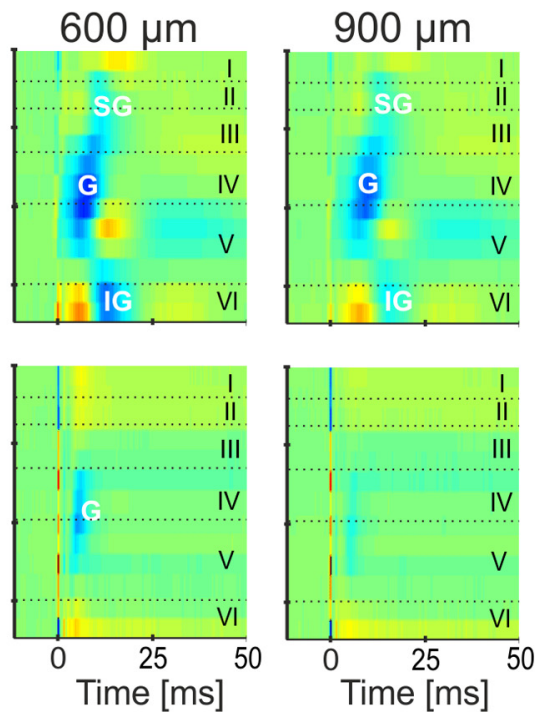
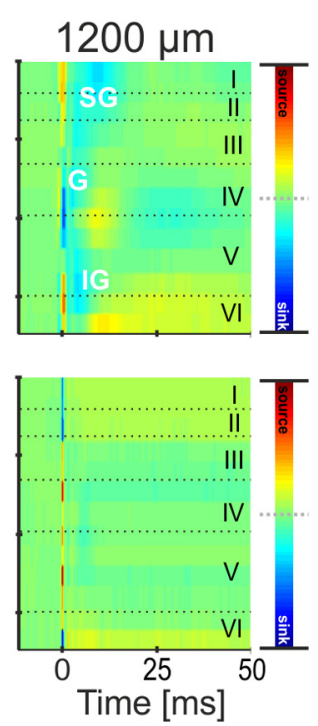

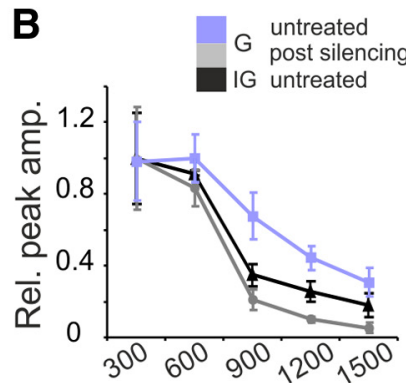

Lateral distance $[\mu \mathrm{m}]$

Figure 6. Lateral extent of recurrent corticoefferent feedback driven by infragranular ICMS. $A$, Example of CSD profiles evoked by infragranular ICMS at sites up to a lateral distances of $1200 \mu \mathrm{m}$ to the recording site (CSD profiles at $1500 \mu \mathrm{m}$ distance are not shown, because they were identical to those at $1200 \mu \mathrm{m}$ ). However, persisting granular sinks after cortical silencing were found only within a spatial range of up to $600 \mu \mathrm{m}$ around the stimulation site. Notably, the strong infragranular sink in untreated cortex extends over a similar spatial range of $300-600 \mu \mathrm{m}$. $\boldsymbol{B}$, Normalized mean peak amplitude averaged across animals as a function of distance showed a larger horizontal trans-synaptic spread of activity evoked by ICMS in granular compared with infragranular layers. After cortical silencing, the lateral spread of the granular sink was highly similar to the lateral spread of the untreated infragranular sink.

infragranular layers via topographically organized first-order thalamocortical relays.

\section{Perceptual role of corticocortical and recurrent corticoefferent projection systems}

Finally, to investigate the functional role of corticoefferent feedback and corticocortical feedforward pathways in perception, we performed a behavioral signal detection analysis of layer-specific ICMS. Animals $(n=10)$ were initially trained in a Go/NoGo shuttlebox task to detect monopolar ICMS (300 ms pulse trains, 100 pps, $80 \mu \mathrm{A}$, same single-pulse parameters as used for CSD experiments), applied to three different laminar depths in each of the 12 training sessions (Fig. 7A, left).

Based on signal detection theory, the $d^{\prime}$ of animals was used to quantify the perceptual effects caused by ICMS for each stimulation depth, independent of experimental conditions biasing the response of the animal (Deliano et al., 2009). In the 12th session of training, animals had reached detection performance significantly above threshold (paired-sample Student's $t$ tests, Bonferroni-corrected, $\left.\alpha^{\star}=0.017\right)$ with granular $(1.81 \pm 0.28$, $p=0.016)$ and infragranular $(1.69 \pm 0.19, p=0.006)$ ICMS, but not with supragranular ICMS $(0.49 \pm 0.39, p=0.225$; Fig. $7 B)$. After initial training, we systematically varied current amplitudes $(5-100 \mu \mathrm{A})$ to assess detection sensitivity. In the tested amplitude range, detection sensitivity increased above threshold with increasing strength of granular and infragranular ICMS, whereas only a weak increase not reaching the threshold criterion was found with supragranular ICMS (Fig. 7C; two-way rmANOVA with significant main effects and interaction of factors stimulation amplitude and stimulation depth, $\alpha^{\star}=0.05$; Table 1, 1.13).

For psychometric analysis, the stimulus amplitude for reaching a defined detection criterion of $d^{\prime}=1.0$, corresponding to a signal strength of $1 \mathrm{SD}$ above noise, was determined for each animal and stimulation depth. As only 3 of 10 animals reached the criterion with supragranular ICMS, this condition was excluded from further analysis. The detection of infragranular ICMS was reached at a significantly lower stimulus amplitude than that of granular ICMS $\left(\mathrm{ICMS}_{\mathrm{V}-\mathrm{VI}}, 35.60 \pm 2.88 \mu \mathrm{A}, \mathrm{ICMS}_{\mathrm{III}-\mathrm{IV}}, 50.18 \pm 4.05\right.$ $\mu \mathrm{A}$; paired-sample Student's $t$ test, $p<0.001$; Fig. $7 E)$.

To further distinguish the effects of corticoafferent and corticoefferent activation on perception, bipolar ICMS (BP-ICMS) was applied in the same individuals in the next block of training. BP-ICMS more effectively recruits neuronal fibers running parallel to the electrode tips, preferably in the direction of the cathodic pole compared with nonparallel fibers (Ranck, 1975; see also Fig. 7A). Layer-specific and spatially directed BP-ICMS was delivered at a different polarity between the radially implanted supragranular/granular and infragranular/granular electrode pairs (Fig. $7 A$, right). Similar to monopolar stimulation, mean detection sensitivity reached higher levels with infragranular BPICMS configurations than with supragranular BP-ICMS configurations. At low stimulus amplitudes $(<20 \mu \mathrm{A})$, however, detection sensitivity with infragranular cathodic BP-ICMS (i.e., with preferential excitation in corticoefferent direction) was significantly higher than with all other BP-ICMS configurations (Fig. $7 D, E$; rmANOVA, $\alpha^{*}=0.05$, significant main effects and interaction of factors stimulation amplitude and BP-ICMS configuration; Table 1, 1.14). A pairwise statistical comparison (paired-sample Student's $t$ tests, Bonferroni-corrected, $\alpha^{\star}=$ $0.008)$ of the stimulus amplitudes at the predefined detection criterion $\left(d^{\prime}=1\right)$ between BP-ICMS configurations (Fig. 7E, right) showed that infragranular cathodic ICMS required the lowest amplitude for reaching the criterion $(20.50 \pm 5.60 \mu \mathrm{A}, p \leq$ $0.003)$. No significant differences were found among all other conditions (supragranular anodic, $47.77 \pm 10.67 \mu \mathrm{A}$; supragranular cathodic, $38.43 \pm 6.29 \mu \mathrm{A}$; infragranular anodic, $31.61 \pm 5.32 \mu \mathrm{A} ; p \geq 0.063)$. The mean hit reaction times of $2.00 \pm 0.18 \mathrm{~s}$ for MP-ICMS and of $1.96 \pm 0.2 \mathrm{~s}$ for BP-ICMS show that on average two ICMS trains were presented before the animals responded. As there were no significant differences of hit reaction time across conditions ( $r m A N O V A, \alpha^{*}=0.05$; for MP- 
ICMS and BP-ICMS, no significant effects of factors stimulation depth or "ICMS configuration" and stimulation amplitude, as well as no significant interactions; Table 1, 1.15 and 1.16), observed differences in detection behavior cannot be explained by the hit reaction time or the number of presented ICMS trains. Thus, behavioral detection of ICMS was most sensitive when ICMS optimally recruited corticoefferent pathways (i.e., the entry point for dopamine-sensitive recurrent positive feedback to granular layers determined by our electrophysiological experiments).

\section{Discussion}

In this study, in vivo CSD analysis revealed an immediate layer-dependent and timedependent influence of dopaminergic neurotransmission on stimulus-evoked processing in primary auditory cortex after the administration of the $\mathrm{D}_{1} / \mathrm{D}_{5}$ agonist SKF38393. SKF38393 increased toneevoked synaptic activity in infragranular corticoefferent output layers. Resulting positive recurrent feedback from infragranular output to granular input layers at a delay of $\sim 6 \mathrm{~ms}$ prolonged local thalamocortical input. This network effect of dopaminergic modulation promoted sustained and strengthened horizontal corticocortical interactions during later phases of processing. A detailed circuit analysis combining direct excitation of corticoefferent pathways by infragranular ICMS and cortical silencing with muscimol revealed an extracortical recurrent feedback input to granular layers with an onset latency of $6.56 \pm 1.39$ ms. This recurrent feedback circuit explains the observed correlation peak at $\sim 6$ $\mathrm{ms}$ and the corresponding peak latency difference between $G$ and IG sinks with dopamine-enhanced corticoefferent output. Mimicking the increase of auditory infragranular activation (asymmetric crosslaminar activation pattern) under dopaminergic influence, direct excitation of corticoefferent pathways by infragranular ICMS was most effective in generating a behaviorally detectable signal. Otherwise, granular ICMS yielded a symmetric cross-

laminar activation pattern dominated by granular input reminiscent of acoustic stimulation before the administration of SKF38393, and was less effective in eliciting stimulus detection. Supragranular ICMS led to a local, polysynaptic activation of the cortex suppressed by cortical silencing, but failed to elicit crosslaminar processing. This activation might reflect fast and local inhibition across layers, as demonstrated before by intracellular recordings in primary visual cortex (Chung and Ferster, 1998). Despite a cross-laminar activation of distal microcircuits via polysynaptic horizontal pathways, supragranular ICMS did not provide a behaviorally detectable signal.
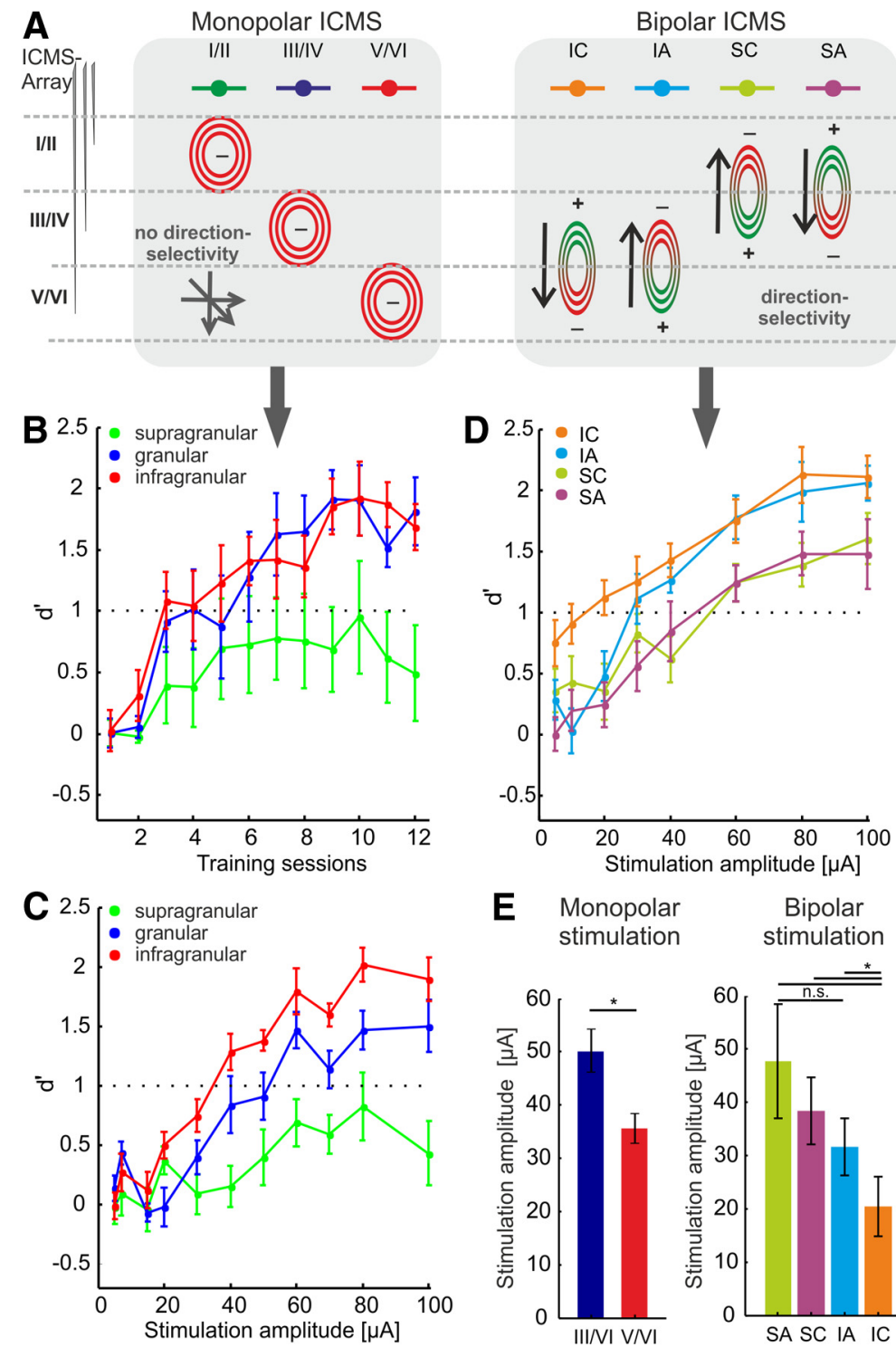

E

E Monopolar

Bipolar

stimulation

stimulation
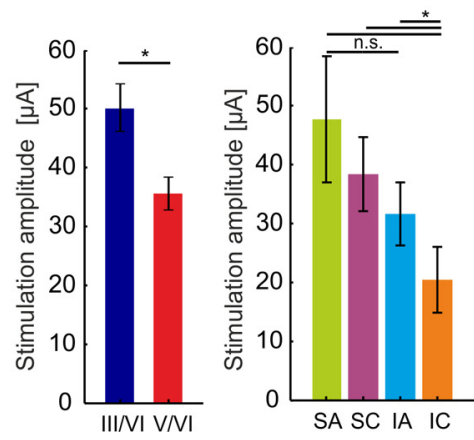

Figure 7. Behavioral detection of layer-specific ICMS. A, Monopolar (left) and bipolar (right) electrical stimulus configurations applied to each individual animal. Black arrows indicate the preferred orientation of fiber activation in the different bipolar configurations (BP-ICMS; IC, IG cathodic; IA, IG anodic; SC, SG cathodic; SA, SG anodic). See also graphic illustration on the right (Ranck, 1975). B, During initial avoidance learning, a sequence of monopolar layer-specific pulse trains ( $80 \mu \mathrm{A}, 300 \mathrm{~ms}$ ) served as the conditioned stimulus. Stimulation depth varied randomly across trials of a session. The development of detection performance over training sessions was quantified separately for each stimulation depth by mean $d^{\prime}$ values ( \pm SEM) across all animals $(n=10)$. C, Psychometric analysis of mean $d^{\prime}$ values ( \pm SEM) across animals as a function of stimulation amplitude $(5-100 \mu \mathrm{A})$ showed an earlier increase of detection sensitivity with infragranular ICMS $(35.60 \pm 2.88 \mu \mathrm{A})$ compared with ICMS in other layers. See also $E$. D, The mean $d^{\prime}$ value ( \pm SEM) of BP-ICMS configurations was lowest with the preferential activation of infragranular fibers in a corticoefferent direction (IC $20.50 \pm 5.60 \mu \mathrm{A}$ ). See also $\boldsymbol{A} . \boldsymbol{E}$, Quantitative comparison of stimulation amplitudes (in microamperes) at the threshold criterion of $d^{\prime}=$ 1.0 determined individually in each animals, and for each monopolar and bipolar stimulation condition. Again, the current amplitudes required for behavioral detection were lowest with infragranular corticoefferent excitation.

\section{Specificity of local recurrent corticothalamic feedback}

In addition to unspecific excitation of bypassing axonal fibers, trans-synaptic ICMS effects can be highly specific with respect to the stimulation site (Chung and Ferster, 1998; Tehovnik et al., 2005; Histed et al., 2009). In our study, we manipulated layerand direction-dependent ICMS effects by cortical silencing of polysynaptic, intracortically relayed activity (Happel et al., 2010). Residual sink activity therefore could have arisen only from a monosynaptic granular activation, which is largely unaffected by muscimol. This monosynaptic cortical input could in principle derive from direct orthodromic or antidromic excitation of affer- 
ent fibers in passage, and their collaterals, terminating in granular layers. However, it is expected that intracortical monosynaptic propagation of direct excitation within the observed local activation range of $\sim 600 \mu \mathrm{m}$ will occur at latencies of $<2 \mathrm{~ms}$, when taking into account the known conductance velocities of axonal fibers $(\sim 0.3-5 \mathrm{~mm} / \mathrm{ms})$ and synaptic transmission delays $(0.8-$ $1.0 \mathrm{~ms}$ ) in the cortex (Tsumoto and Suda, 1982). Thus, observed postsilencing onset latencies of $6.25 \pm 1.55 \mathrm{~ms}$ strongly suggest an extracortical polysynaptic relay of granular input (Histed et al., 2009; Logothetis et al., 2010).

Focal, persistent granular activation matched with the termination of thalamocortical projections from the first-order (lemniscal) auditory thalamus, both across layers and along the tonotopic axis (Ohl et al., 2000; Kawai et al., 2007; Happel et al., 2010). This granular activation was most effectively recruited by excitation of infragranular corticoefferent output layers, suggesting recurrent cortico-thalamocortical feedback. Disynaptic feedback between thalamus and cortex has been demonstrated before in the macaque visual system with delays of 3-8 ms (Briggs and Usrey, 2007), which is similar to the delays observed in our study. The cortico-thalamocortical feedback proposed by our study could complete the fast loop between cortex and thalamus described by Briggs and Usrey (2007) through fast and brief glutamatergic currents via ionotropic receptors, consistent with further evidence challenging the view of exclusively slow modulatory feedback (Covic and Sherman, 2011; Bastos et al., 2012). Also, layer V pyramidal cells could potentially contribute to the feedback via topographically organized, polysynaptic pathways (Rouiller and Durif, 2004; Budinger et al., 2006).

\section{Differential effects of direct corticoefferent and horizontal corticocortical excitation on stimulus detection}

Highest behavioral detection performance (quantified by $d^{\prime}$ ) was found with electrical stimulation of the infragranular corticoefferent fibers (Fig. 7). In contrast, supragranular ICMS activating distal cortical microcircuits, but inhibiting local cross-laminar processing and corticoefferent feedback (Fig. 4A), was insufficient for detection. Hence, the neural circuitry underlying salient signal detection essentially includes the recruitment of local corticoefferent feedback in sensory cortex providing sustained reentrant cortical input. Notably, pharmacological silencing of auditory cortex with muscimol, as in our study, can effectively block performance in trained rats in various auditory tasks (Gerstein et al., 2002; Jaramillo and Zador, 2011). Activation of polysynaptic horizontal networks thus plays an essential role in the readout and interpretation of stimulus information (Hickmott and Merzenich, 1998; Sakai and Suga, 2002; Adesnik and Scanziani, 2010), as further indicated by learning-related changes of ongoing auditory cortical activity patterns during the behavioral interpretation of ICMS (Deliano et al., 2009). Monopolar granular ICMS at higher current amplitudes over $50 \mu \mathrm{A}$ and all BPICMS configurations also yielded detectable signals, which can be explained by the increase of effective current spread with amplitude, and the resulting decrease of layer and/or direction selectivity of ICMS.

\section{Functions of dopaminergic neuromodulation in sensory cortex on a systems level}

Effects of dopamine on neocortical circuits have been studied almost exclusively in prefrontal cortex (PFC). On a cellular level, dopamine has complex, often opposing effects in both pyramidal cells and interneurons (Seamans and Yang, 2004; Tritsch and Sabatini, 2012). Coherent effects of dopamine so far have only been predicted in simulations of recurrent networks in which dopamine enhanced sustained synaptic inputs and stabilized persistent modes of activation (Durstewitz et al., 2000; Ashby and Casale, 2003). Functionally, persistent activation has been related to the maintenance of internal representations during delay periods of a task in many subcortical and cortical regions including sensory cortex (Curtis and Lee, 2010).

Our study shows that dopaminergic modulation led to a sustained sensory cortical activation through positive recurrent feedback between cortex and thalamus, a mechanism that has also been proposed for persistent PFC activation (Watanabe and Funahashi, 2012). $\mathrm{D}_{1} / \mathrm{D}_{5}$ stimulation increased initial infragranular activation presumably by directly influencing ionotropic glutamatergic transmission (Seong and Carter, 2012; Tritsch and Sabatini, 2012). Enhanced correlation between infragranular output and granular input at a granular delay of $\sim 6 \mathrm{~ms}$ suggests that dopamine enhanced the gain of early, local corticoefferent feedback to AI. Such immediate effects of dopamine have also been implicated in triggering orienting responses, eliciting attention, promoting rapid stimulus assessment and detection, as well as enhancing cognitive processing (Bromberg-Martin et al., 2010). Runaway excitation of positive feedback could be prevented through refractory periods, dissipation of energy via increased transmembrane conductance, balance of excitation and inhibition, and short-term synaptic plasticity (Douglas and Martin, 2007). Local feedback could increase recurrent intracortical excitation (Liu et al., 2007), overcoming local inhibition and boosting widespread horizontal synaptic interactions (Lamme et al., 1998; Douglas and Martin, 2007). This would explain how dopamine-modulated local recurrent feedback during early phases strengthened sustained horizontal corticocortical interactions in later phases of auditory processing (Lavin et al., 2005). Strengthened horizontal network interactions might then serve the selection of task-related neuronal ensembles, allowing for the readout of behaviorally relevant information stored by the intracortical synaptic connectivity (Hickmott and Merzenich, 1998; Sakai and Suga, 2002; Adesnik and Scanziani, 2010). In this respect, dopamine function contrasts with cholinergic/norepinephrinic network effects, which are thought to suppress later and feedback pathways in sensory cortex to enhance the local afferent input and feedforward processing (Hasselmo, 1995; Metherate et al., 2005; Kawai et al., 2007; Edeline, 2012).

Microdialysis studies revealed a transient dopamine release in both auditory cortex and medial PFC during successful auditory learning (Stark et al., 2008). Sustained activation in sensory cortex might therefore reflect cognitive functions similar to those in PFC networks (i.e., the maintenance of task-related information over extended time periods or the enhancement of processing of nonsalient, but important stimuli; Bromberg-Martin et al., 2010). On a behavioral level, stimulation of infragranular output layers mimicking cross-laminar auditory activation patterns under dopaminergic influence yielded the highest behavioral signal detection performance. Such an effect has been hypothesized by previous theoretical network studies on dopaminergic gain modulation (Servan-Schreiber et al., 1990; Ashby and Casale, 2003). Improved signal detection, however, might actually rely on the described network effects resulting from dopaminergic gain modulation, which could serve such a function well. Moreover, dopamine-modulated corticoefferent circuits could further regulate higher-order cortical and various subcortical structures, potentially affecting sensory, motor, limbic, and higher cognitive processes in a fast and direct way. Also, immediate dopamine effects in sensory cortex could mediate the behavioral effects of 
dopamine on learning and memory on longer time scales (Stark and Scheich, 1997; Ohl and Scheich, 2005; Schicknick et al., 2008, 2012; Stark et al., 2008).

Finally, our results might have clinical implications for understanding the therapeutic effect of drugs interacting with the dopaminergic system, for instance methylphenidate or amphetamines, which are commonly used for treating children and adults with attention deficit disorder (Schonwald and Lechner, 2006). Gain modulation of sensory integration via recurrent corticoefferent feedback is a potentially relevant neural substrate for positive treatment effects and might stimulate new therapeutic interventions for developmental sensory-processing disorders, including dyslexia or learning disabilities in school children (Davies et al., 2009).

\section{References}

Adesnik H, Scanziani M (2010) Lateral competition for cortical space by layer-specific horizontal circuits. Nature 464:1155-1160. CrossRef Medline

Ashby FG, Casale MB (2003) A model of dopamine modulated cortical activation. Neural Netw 16:973-984. CrossRef Medline

Bastos AM, Usrey WM, Adams RA, Mangun GR, Fries P, Friston KJ (2012) Canonical microcircuits for predictive coding. Neuron 76:695-711. CrossRef Medline

Briggs F, Usrey WM (2007) A fast, reciprocal pathway between the lateral geniculate nucleus and visual cortex in the macaque monkey. J Neurosci 27:5431-5436. CrossRef Medline

Bromberg-Martin ES, Matsumoto M, Hikosaka O (2010) Dopamine in motivational control: rewarding, aversive, and alerting. Neuron 68:815-834. CrossRef Medline

Budinger E, Heil P, Hess A, Scheich H (2006) Multisensory processing via early cortical stages: connections of the primary auditory cortical field with other sensory systems. Neuroscience 143:1065-1083. CrossRef Medline

Campbell MJ, Lewis DA, Foote SL, Morrison JH (1987) Distribution of choline acetyltransferase-, serotonin-, dopamine-P-hydroxylase-, tyrosine hydroxylase-immunoreactive fibers in monkey primary auditory cortex. J Comp Neurol 261:209-220. CrossRef Medline

Chung S, Ferster D (1998) Strength and orientation tuning of the thalamic input to simple cells revealed by electrically evoked cortical suppression. Neuron 20:1177-1189. CrossRef Medline

Covic EN, Sherman SM (2011) Synaptic properties of connections between the primary and secondary auditory cortices in mice. Cereb Cortex 21: 2425-2441. CrossRef Medline

Curtis CE, Lee D (2010) Beyond working memory: the role of persistent activity in decision making. Trends Cogn Sci 14:216-222. CrossRef Medline

Dahmen JC, Keating P, Nodal FR, Schulz AL, King AJ (2010) Adaptation to stimulus statistics in the perception and neural representation of auditory space. Neuron 66:937-948. CrossRef Medline

Davies PL, Chang WP, Gavin WJ (2009) Maturaration of sensory gating performance in children with an without sensory processing disorders. Int J Psychophysiol 72:187-197. CrossRef Medline

Deliano M, Scheich H, Ohl FW (2009) Auditory cortical activity after intracortical microstimulation and its role for sensory processing and learning. J Neurosci 29:15898-15909. CrossRef Medline

Douglas RJ, Martin KA (2007) Mapping the matrix: the ways of neocortex. Neuron 56:226-238. CrossRef Medline

Durstewitz D, Seamans JK, Sejnowski TJ (2000) Neurocomputational models of working memory. Nat Neurosci 3 [Suppl]:1184-1191. CrossRef Medline

Edeline JM (2012) Beyond traditional approaches to understanding the functional role of neuromodulators in sensory cortices. Front Behav Neurosci 6:45. CrossRef Medline

Friston KJ, Shiner T, FitzGerald T, Galea JM, Adams R, Brown H, Dolan RJ, Moran R, Stephan KE, Bestmann S (2012) Dopamine, affordance and active inference. PLoS Comput Biol 8:e1002327. CrossRef Medline

Gerstein G, Kirkland K, Musial P, Talwar S (2002) Recordings, behavior and models related to corticothalamic feedback. Philos Trans R Soc B Biol Sci 357:1835-1841. CrossRef Medline
Happel MF, Jeschke M, Ohl FW (2010) Spectral integration in primary auditory cortex attributable to temporally precise convergence of thalamocortical and intracortical input. J Neurosci 30:11114-11127. CrossRef Medline

Hasselmo ME (1995) Neuromodulation and cortical function: modeling the physiological basis of behavior. Behav Brain Res 67:1-27. CrossRef Medline

Hickmott PW, Merzenich MM (1998) Single-cell correlates of a representational boundary in rat somatosensory cortex. J Neurosci 18:4403-4416. Medline

Histed MH, Bonin V, Reid RC (2009) Direct activation of sparse, distributed populations of cortical neurons by electrical microstimulation. Neuron 63:508-522. CrossRef Medline

Jaramillo S, Zador AM (2011) The auditory cortex mediates the perceptual effects of acoustic temporal expectation. Nat Neurosci 14:246-251. CrossRef Medline

Kawai H, Lazar R, Metherate R (2007) Nicotinic control of axon excitability regulates thalamocortical transmission. Nat Neurosci 10:1168-1175. CrossRef Medline

King AJ (1997) Signal selection by cortical feedback. Curr Biol 7:R85-R88. CrossRef Medline

Kraus M, Schicknick H, Wetzel W, Ohl F, Staak S, Tischmeyer W (2002) Memory consolidation for the discrimination of frequency-modulated tones in Mongolian gerbils is sensitive to protein-synthesis inhibitors applied to the auditory cortex. Learn Mem 9:293-303. CrossRef Medline

Krimer LS, Jakab RL, Goldman-Rakic PS (1997) Quantitative threedimensional analysis of the catecholaminergic innervation of identified neurons in the macaque prefrontal cortex. J Neurosci 17:7450-7461. Medline

Lamme VA, Supèr H, Spekreijse H (1998) Feedforward, horizontal, and feedback processing in the visual cortex. Curr Opin Neurobiol 8:529-535. CrossRef Medline

Lavin A, Nogueira L, Lapish CC, Wightman RM, Phillips PE, Seamans JK (2005) Mesocortical dopamine neurons operate in distinct temporal domains using multimodal signaling. J Neurosci 25:5013-5023. CrossRef Medline

Liu BH, Wu GK, Arbuckle R, Tao HW, Zhang LI (2007) Defining cortical frequency tuning with recurrent excitatory circuitry. Nat Neurosci 10: 1594-1600. CrossRef Medline

Logothetis NK, Augath M, Murayama Y, Rauch A, Sultan F, Goense J, Oeltermann A, Merkle H (2010) The effects of electrical microstimulation on cortical signal propagation. Nat Neurosci 13:1283-1291. CrossRef Medline

Metherate R, Kaur S, Kawai H, Lazar R, Liang K, Rose HJ (2005) Spectral integration in auditory cortex: mechanisms and modulation. Hear Res 206:146-158. CrossRef Medline

Mitzdorf U (1985) Current source-density method and application in cat cerebral cortex: investigation of evoked potentials and EEG phenomena. Physiol Rev 65:37-100. Medline

Müller-Preuss P, Mitzdorf U (1984) Functional anatomy of the inferior colliculus and the auditory cortex: current source density analyses of clickevoked potentials. Hear Res 16:133-142. CrossRef Medline

Ohl FW, Scheich H (2005) Learning-induced plasticity in animal and human auditory cortex. Curr Opin Neurobiol 15:470-477. CrossRef Medline

Ohl FW, Wetzel W, Wagner T, Rech A, Scheich H (1999) Bilateral ablation of auditory cortex in Mongolian gerbil affects discrimination of frequency modulated tones but not of pure tones. Learn Mem 6:347-362. Medline

Ohl FW, Scheich H, Freeman WJ (2000) Topographic analysis of epidural pure-tone-evoked potentials in gerbil auditory cortex. J Neurophysiol 83:3123-3132. Medline

Ohl FW, Scheich H, Freeman WJ (2001) Change in pattern of ongoing cortical activity with auditory category learning. Nature 412:733-736. CrossRef Medline

Phillipson OT, Kilpatrick IC, Jones MW (1987) Dopaminergic innervation of the primary visual cortex in the rat, and some correlations with human cortex. Brain Res Bull 18:621-633. Medline

Ranck JB Jr (1975) Which elements are excited in electrical stimulation of mammalian central nervous system: a review. Brain Res 98:417-440. CrossRef Medline 
Rouiller EM, Durif C (2004) The dual pattern of corticothalamic projection of the primary auditory cortex in macaque monkey. Neurosci Lett 358: 49-52. CrossRef Medline

Sakai M, Suga N (2002) Centripetal and centrifugal reorganization of frequency map of auditory cortex in gerbils. Proc Natl Acad Sci U S A 99: 7108-7112. CrossRef Medline

Sakata S, Harris KD (2009) Laminar structure and sensory-evoked population activity in auditory cortex. Neuron 64:404-418. CrossRef Medline

Scheich H, Heil P, Langner G (1993) Functional organization of auditory cortex in the Mongolian gerbil (Meriones unguiculatus) II. Tonotopic 2-deoxyglucose. Eur J Neurosci 5:898-914. CrossRef Medline

Scheich H, Brechmann A, Brosch M, Budinger E, Ohl FW, Selezneva E, Stark H, Tischmeyer W, Wetzel W (2011) Behavioral semantics of learning and crossmodal processing in auditory cortex: the semantic processor concept. Hear Res 271:3-15. CrossRef Medline

Schicknick H, Schott BH, Budinger E, Smalla KH, Riedel A, Seidenbecher CI, Scheich H, Gundelfinger ED, Tischmeyer W (2008) Dopaminergic modulation of auditory cortex-dependent memory consolidation through mTOR. Cereb Cortex 18:2646-2658. CrossRef Medline

Schicknick H, Reichenbach N, Smalla KH, Scheich H, Gundelfinger ED, Tischmeyer W (2012) Dopamine modulates memory consolidation of discrimination learning in auditory cortex. Eur J Neurosci 35:763-774. CrossRef Medline

Schonwald A, Lechner E (2006) Attention deficit/hyperactivity disorder: complexities and controversies. Curr Opin Pediatr 18:189-195. CrossRef Medline

Schroeder CE, Mehta AD, Givre SJ (1998) A spatiotemporal profile of visual system activation revealed by current source density analysis in the awake macaque. Cereb Cortex 8:575-592. CrossRef Medline

Seamans JK, Yang CR (2004) The principal features and mechanisms of dopamine modulation in the prefrontal cortex. Prog Neurobiol 74:1-58. CrossRef Medline

Seong HJ, Carter AG (2012) D1 receptor modulation of action potential firing in a subpopulation of layer 5 pyramidal neurons in the prefrontal cortex. J Neurosci 32:10516-10521. CrossRef Medline

Servan-Schreiber D, Printz H, Cohen JD (1990) A network model of catecholamine effects: gain, signal-to-noise ratio, and behavior. Science 249: 892-895. CrossRef Medline

Stark H, Scheich H (1997) Dopaminergic and serotonergic neurotransmission systems are differentially involved in auditory cortex learning: a longterm microdialysis study of metabolites. J Neurochem 68:691-697. Medline

Stark H, Rothe T, Deliano M, Scheich H (2008) Dynamics of cortical theta activity correlates with stages of auditory avoidance strategy formation in a shuttle-box. Neurosci 151:467-475. CrossRef

Szymanski FD, Garcia-Lazaro JA, Schnupp JW (2009) Current source density profiles of stimulus-specific adaptation in rat auditory cortex. J Neurophysiol 102:1483-1490. CrossRef Medline

Tehovnik EJ, Slocum WM, Carvey CE, Schiller PH (2005) Phosphene induction and the generation of saccadic eye movements by striate cortex. J Neurophysiol 93:1-19. CrossRef Medline

Tritsch NX, Sabatini BL (2012) Dopaminergic modulation of synaptic transmission in cortex and striatum. Neuron 76:33-50. CrossRef Medline

Tsumoto T, Suda K (1982) Effects of stimulation of the dorsocaudal claustrum on activities of striate cortex neurons in the cat. Brain Res 240:345349. CrossRef Medline

Watanabe Y, Funahashi S (2012) Thalamic mediodorsal nucleus and working. Neurosci Biobehav Rev 36:134-142. CrossRef Medline

Winer JA, Miller LM, Lee CC, Schreiner CE (2005) Auditory thalamocortical transformation: structure and function. Trends Neurosci 28:255-263. CrossRef Medline 